\title{
ANÁLISIS ANTRACOLÓGICO DE LA NECRÓPOLIS DE CRUZ DEL NEGRO. (CARMONA, SEVILLA) ${ }^{1}$
}

\author{
ANTHRACOLOGICAL ANALYSIS OF THE CRUZ DEL NEGRO \\ NECROPOLIS (CARMONA, SEVILLA) \\ por
}

\author{
$M^{\mathrm{a}}$ OLIVA RODRÍGUEZ-ARIZA* \\ JOSÉ ANTONIO ESQUIVEL**
}

RESUMEN Se analizan los carbones recuperados en 68 estructuras de combustión de la necrópolis de incineración de Cruz del Negro. Los resultados obtenidos se han sometido a varios análisis cluster para intentar descubrir, en primer lugar, si la aparición de las distintas especies esta condicionada por factores postdeposicionales y, en segundo, si la aparición de estas responden a la recogida y utilización selectiva de las mismas. A nivel paleoetnobotánico se han descubierto: conjuntos de estructuras que han utilizado las mismas especies vegetales como combustible para realizar la cremación de los cadáveres o ritos funerarios, asociaciones vegetales que pueden tener una distribución diferenciada en el entorno de la necrópolis y a nivel espacial zonas de la necrópolis caracterizadas por la aparición de varios taxones. A nivel paleoecológico se han determinado varias zonas con vegetación natural que parecen denotar unos parámetros bioclimáticos muy parecidos a los actuales, aunque quizás con un poco más de humedad, posiblemente un ombroclima subhúmedo frente al seco actual.

ABSTRACT The carbon recovered at 68 combustion structures at the cremation necropolis of Cruz del Negro (Carmona, Spain) has been analysed. The results have been submitted to several cluster analyses to establish, firstly, whether the appearance of the different plant species is determined by postdepositional factors and, secondly, whether the appearance of these species relates to the gathering and selective use of them. In palaeobotanical terms, groups of structures were found to have used the same plant species as fuel in order to perform either cremations or funerary rites, and these plant associations may have had a differentiated distribution in the surroundings of the necropolis. In spatial

1. Resultados que fueron presentados en el IV International Symposium on Computing and Archaeology, celebrado en Bilbao en 1998.

* Centro Andaluz de Arqueología Ibérica. Edif. B-1. Universidad de Jaén. 23071 Jaén. Correo electrónico: moliva@ ujaen.es

** Departamento de Prehistoria y Arqueología. Facultad de Filosofía y Letras. Universidad de Granada. 18071 Granada. Correo electrónico: esquivel@ugr.es

ISSN: $1133-4525$ ISSN-e: 2255-3924

SPAL 13 (2004): 113-138

http://dx.doi.org/10.12795/spal.2004.113.04 
terms, zones of the necropolis were characterized by the presence of various taxa. In terms of palaeoecology, various zones were determined to have had natural vegetation, apparently denoting bioclimatic parameters very similar to those of today, although perhaps with somewhat more humidity, possibly an subhumid umbroclimate as opposed to the present-day dry one.

Palabras claves Antracología, necrópolis de incineración, Protohistoria.

Key words

Anthracology, cremation necropolis, protohistory.

\section{INTRODUCCIÓN}

La necrópolis de Cruz del Negro se sitúa a $1 \mathrm{Km}$. del casco urbano de Carmona en dirección Noroeste. Se localiza sobre una suave loma ocupada por olivos, en la confluencia de las carreteras que conducen desde Carmona hacia Guadajoz y Lora del Río (Fig. 1).

El descubrimiento de la Cruz del Negro data de 1870, a raíz de la construcción de la línea férrea Carmona-Guadajoz, la cual seccionó en dos mitades el yacimiento, detectándose diversas estructuras funerarias que provocaron una serie de excavaciones, principalmente las llevadas a cabo por R. Pérez y González y J. Vega en 1895 y las realizadas por J. Bonsor entre 1897 y 1905.

Parcialmente publicada en 1899 por su principal excavador, Jorge Bonsor, la necrópolis de Cruz del Negro ha dado origen a abundante bibliografía que avala su importancia como enclave fundamental sobre el que se argumenta buena parte del desarrollo de la sociedad tartésica del Bajo Guadalquivir.

En 1989 se realizó una excavación de emergencia ante la remoción de tierras y la extracción de tierras que destruyen parte de la necrópolis (Gil et al. 1991). En esta campaña se hallaron una serie de estructuras primarias (31 quemaderos y 4 inhumaciones) y 68 estructuras secundarias (hoyos de deposición de urnas cinerarias y vasos de ofrendas).

A partir de esta fecha el estudio y excavación de esta necrópolis se enmarcan de un Proyecto General de Investigación centrado en el estudio de la Sociedad Tartésica en el Bajo Guadalquivir².

\section{SITUACIÓN BIOGEOGRÁFICA ACTUAL}

En la actualidad los parámetros bioclimáticos registrados en Carmona (Sevilla) durante doce años, son los siguientes (Asensi y Diez 1987):

$\mathrm{T}$ (Temperatura media anual): 17,1

m (Media de las mínimas del mes más frío): 5,5

M (Media de las máximas del mes más frío): 12,3

It (Indice de termicidad): 349

P (Precipitación anual en mm.): 580

2. Proyecto: "Cambio cultural y mecanismos de transformación de la Sociedad Tartésica durante el Bronce Final y el Orientalizante en el Bajo Guadalquivir: el caso de Carmona, Setefilla y el Carambolo”, dirigido por F. Amores Carredano, M.E. Aubet Semmler, M.S. Gil de los Reyes y M. Puya García de Leaniz, aprobado por la Dirección General de Bienes Culturales de la Junta de Andalucía. 


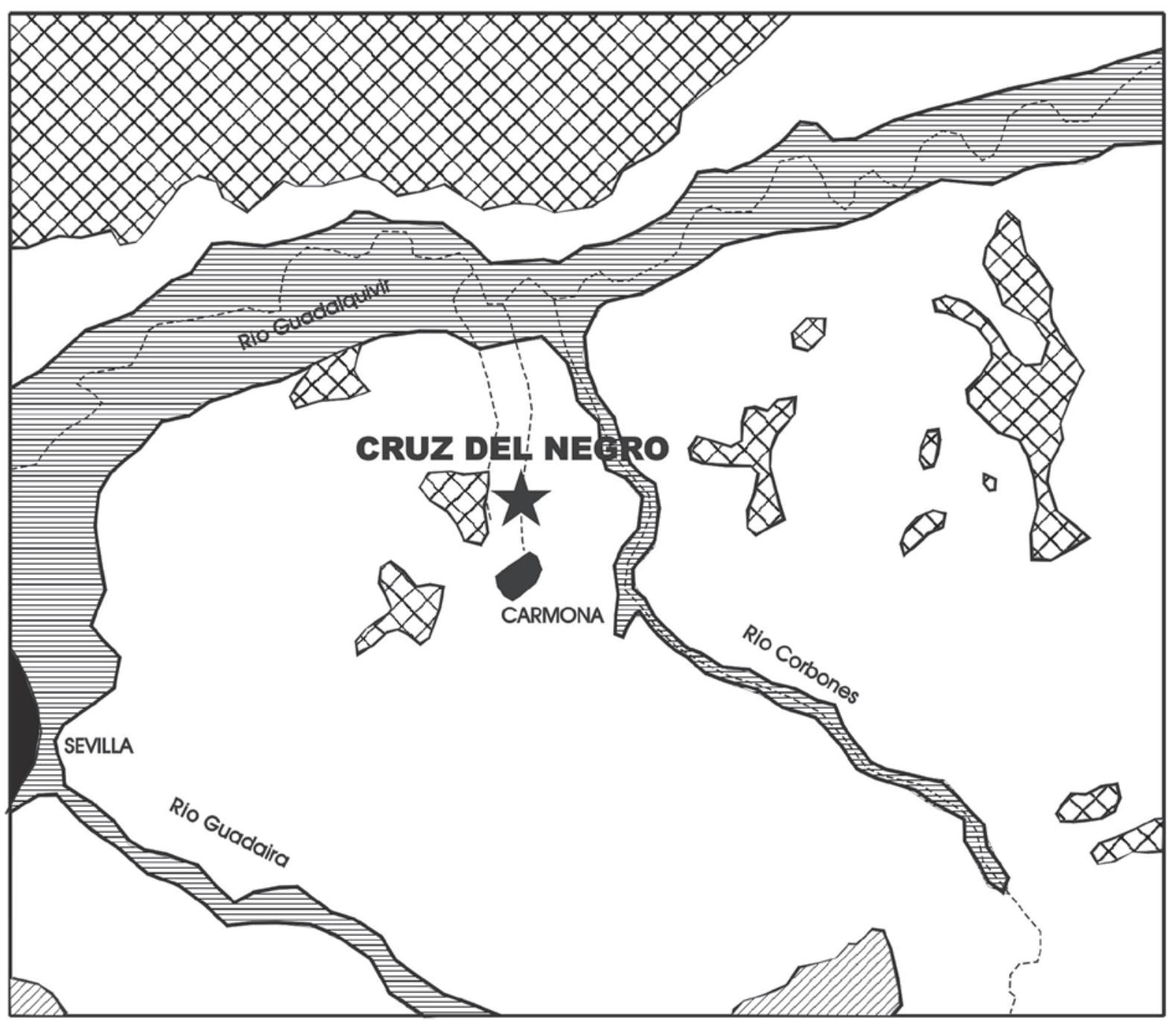

PISO TERMOMEDITERRÁNEO

Encinares silicícolas secos-subhúmedos

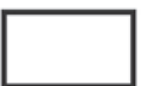

Encinares basófilos secos-subhúmedos

Alcornocales silicícolas subhúmedos

Geomegaseries riparias mediterráneas y regadios

Figura 1: Mapa de series de vegetación (a partir de Rivas Martínez 1988) y localización del yacimiento. 
Estas condiciones climáticas hacen que podamos incluir el territorio de Carmona dentro del piso bioclimático Mesomediterráneo inferior seco (Asensi y Diez 1987: 205), aunque estaciones cercanas como Lora del Río, Écija, Alcalá de Guadaira y Sevilla registran parámetros bioclimáticos muy similares y se incluyen dentro del piso Termomediterráneo superior seco. Por tanto, nos encontramos en una zona de contacto entre los pisos bioclimáticos Termo- y Mesomediterráneo, produciendo que a nivel potencial se puedan desarrollar varias series de vegetación, dependiendo de factores edáficos y ombroclimáticos. Así, la presencia de materiales diversos convierte a esta zona, cuya potencialidad general es la de un encinar termófilo, en un mosaico donde alcornocal (Oleo-Querceto suberis) y encinar (Oleo-Querceto rotundifoliae) se instalan dependiendo de si el sustrato es silíceo o básico y el ombroclima subhúmedo o seco (Fig. 1). A nivel biogeográfico este territorio se incluye dentro del sector Hispalense de la provincia Bética (Rivas Martínez 1987).

Actualmente la vegetación natural, al desarrollarse sobre suelos con una potencialidad agrícola acusada, ha desaparecido prácticamente y sólo pueden encontrarse pequeños bosques relegados a zonas marginales y zonas ecológicas desfavorables. En general, el área está dedicada al cultivo de cereales, se encuentra adehesada o utilizada por viñedos.

\section{EL ANÁLISIS ANTRACOLÓGICO}

El camino que ha seguido un arbusto o árbol desde su hábitat pasado hasta la actualidad en que, los restos de éstos, son interpretados en términos paleoecológicos, es largo y está jalonado de etapas que modifican la correlación simple entre flora determinada y vegetación pasada. Todo espectro antracológico es una información muy resumida de la vegetación de origen y no habla directamente sobre la masa total de madera quemada, el área de aprovisionamiento, el grado de degradación y la estructura de la vegetación, aunque podamos inferir estos datos con la ayuda de la paleobotánica y métodos estadísticos. Este proceso de transformación de información en antracología, en el que se pasa de la vegetación pasada a la interpretación paleoecológica, se puede resumir en cuatro grandes etapas (Rodríguez-Ariza 1992; 1993 y 2004).

1. Etapa de utilización de la vegetación, ligada a las prácticas humanas de recogida de leña en el medioambiente en torno al asentamiento y su utilización en el espacio doméstico.

2. Etapa de deformación del espectro antracológico donde intervienen factores de diversa índole: químicos (existe una reducción de masa a través de la carbonización) y físicos y medioambientales (el carbón depositado en los sedimentos arqueológicos está sujeto a procesos postdeposicionales que distorsionan y/o filtran la información).

3. Etapa de recuperación del material antracológico, ligada a la recuperación global del registro arqueológico, aunque para la recuperación del carbón vegetal, en algunas ocasiones, por su naturaleza, sea necesario la utilización de técnicas específicas como la de flotación.

4. Etapa de estudio o método de trabajo en Antracología en que, una vez obtenida la muestra de carbón del yacimiento, ésta es analizada, medida y contada, obteniendo la muestra antracológica sobre la que se realiza la interpretación paleoecológica. Esta fase es la que caracteriza a la antracología, confiriéndole una personalidad propia dentro de las ciencias paleobotánicas.

Al final de este proceso se obtiene un conocimiento importante, no sólo de la vegetación del pasado, sino también de la sociedad a través de la utilización que hace de esta vegetación.

La relación sociedad-medio vegetal, origen de la investigación antracológica, es la primera etapa de este proceso, pero a la vez la última, pues los datos antracológicos han de servirnos para 
redefinir y elaborar un modelo paleoetnobotánico de cada comunidad prehistórica, a la par que nos delimita las interpretaciones paleoecológicas de los resultados.

Hay que señalar una serie implicaciones que, a priori, tienen diversos tipos de yacimientos arqueológicos, los cuales, según las actividades realizadas en ellos, proporcionarán datos con un mayor valor paleobotánico o paleoetnológico. Así, las necrópolis presentan una serie de características de gran valor cultural, en el que el estudio de los procesos deposicionales y postdeposicionales es fundamental para determinar la utilización y/o reutilización de las sepulturas y poder enmarcarlas a nivel cronológico. Schiffer (1976:31-32) habla del enterramiento del muerto como un proceso deposicional, así como la colocación de los ajuares.

El carácter de conjunto cerrado de los enterramientos confiere a la madera encontrada en ellos, un alto valor para el conocimiento de los diversos rituales y materiales empleados en las ceremonias en honor de los muertos. Así podemos encontrar restos de ataúdes y tablas usadas como protección, además de utensilios de madera y mangos de diversos útiles.

En las necrópolis de inhumación no es frecuente encontrar carbones, sólo aparecen como filtraciones de depósitos más modernos o procedentes de fuegos ocasionales realizados en las proximidades. En las de incineración, a menudo, los restos óseos son guardados junto con los restos de la pira en urnas, por lo que carbones procedentes de la madera utilizada en el ritual pueden estudiarse, dando una valiosa información sobre la utilización de especies leñosas con fines específicos, dentro de procesos de reproducción ideológica. Se puede afirmar que las necrópolis se constituyen en uno de los principales contextos arqueológicos donde podemos encontrar la utilización de recursos vegetales como medios de reproducción ideológica; así como la buena conservación, en muchos casos, de útiles de madera nos informa sobre las relaciones de producción existentes y la situación dentro de la jerarquía social que ocupan los distintos individuos (Miller 1991).

Cuestiones como la utilización de una u otra especie, el poder calorífico de éstas, la asociación de especies utilizadas en cada una de las incineraciones, la asociación de conjuntos en base a la vegetación quemada, etc. nos pueden aportar datos de orden paleoecológico: conocimiento de las especies existentes, grado de disponibilidad en el entorno inmediato, estadio de evolución o degradación, pero también de orden paleoetnológico o arqueológico, como son: existencia de rituales diferenciados en base a agrupaciones familiares y/o sociales y asociaciones cronológicas o espaciales de conjuntos.

\section{EL ANÁLISIS DE LOS RESULTADOS}

\section{III.1. Análisis de las muestras}

Al existir carbón de numerosas estructuras, recuperado en varias campañas de excavación y con distintos métodos de recogida, existía la posibilidad que los resultados cualitativos pudieran verse afectados por estas variables. Asimismo, el carbón presentaba diferentes estados de conservación y el número y tamaño de los fragmentos era muy variable, por lo que era necesario evaluar como estas variables de tipo cualitativo de la muestra podían haber influido en la aparición o no de los distintos taxones y si los resultados estaban sesgados o no por una determinada variable. Con ese fin se han codificado todas las variables de las distintas muestras (Tabla 1), donde cada variable puede presentar los siguientes estados:

ISSN: 1133-4525 ISSN-e: 2255-3924 
TABLA 1: Variables cualitativas de las muestras analizadas. CRUZ DEL NEGRO

\begin{tabular}{|c|c|c|c|c|c|c|c|}
\hline Conjuntos & Campaña & Recogida & $\begin{array}{c}\text { Cantidad } \\
\text { Muestra }\end{array}$ & $\begin{array}{c}\text { Tamaño } \\
\text { Carbones }\end{array}$ & $\begin{array}{c}\text { Muestra } \\
\text { analizada }\end{array}$ & $\begin{array}{l}\text { Estado } \\
\text { Muestra }\end{array}$ & $\begin{array}{l}\mathrm{N}^{\circ} \text { de } \\
\text { Taxones }\end{array}$ \\
\hline 6 & 90 & $\mathrm{~F}$ & 4 & $\mathrm{M}$ & $\mathrm{P}$ & $\mathrm{N}$ & 5 \\
\hline 8 & 90 & $\mathrm{D}$ & 3 & $\mathrm{M}$ & $\mathrm{P}$ & $\mathrm{N}$ & 3 \\
\hline 9 & 90 & $\mathrm{P}$ & 1 & $\mathrm{M}$ & $\mathrm{T}$ & $\mathrm{N}$ & 1 \\
\hline 13 & 90 & $\mathrm{P}$ & 3 & $\mathrm{P}$ & $\mathrm{P}$ & $\mathrm{N}$ & 1 \\
\hline 14 & 90 & $\mathrm{~F}$ & 4 & $\mathrm{G}$ & $\mathrm{P}$ & $\mathrm{N}$ & 5 \\
\hline 16 & 90 & $\mathrm{G}$ & 1 & $\mathrm{M}$ & $\mathrm{T}$ & $\mathrm{N}$ & 1 \\
\hline 20 & 90 & $\mathrm{~F}$ & 4 & $\mathrm{P}$ & $\mathrm{P}$ & $\mathrm{N}$ & 6 \\
\hline 21 & 90 & $\mathrm{G}$ & 1 & $\mathrm{M}$ & $\mathrm{T}$ & $\mathrm{C}$ & 1 \\
\hline 22 & 90 & $\mathrm{~F}$ & 4 & $\mathrm{P}$ & $\mathrm{P}$ & $\mathrm{C}$ & 1 \\
\hline 23 & 90 & $\mathrm{G}$ & 2 & $\mathrm{M}$ & $\mathrm{P}$ & $\mathrm{N}$ & 3 \\
\hline 27 & 90 & $\mathrm{G}$ & 1 & $\mathrm{G}$ & $\mathrm{T}$ & $\mathrm{N}$ & 1 \\
\hline 30 & $90 / 95$ & $\mathrm{P}$ & 3 & $\mathrm{P}$ & $\mathrm{P}$ & $\mathrm{N}$ & 2 \\
\hline 31 & 90 & $\mathrm{~F}$ & 3 & $\mathrm{P}$ & $\mathrm{P}$ & $\mathrm{C}$ & 2 \\
\hline 32 & 90 & $\mathrm{~F}$ & 3 & $\mathrm{P}$ & $\mathrm{P}$ & $\mathrm{N}$ & 1 \\
\hline 33 & 90 & $\mathrm{~F}$ & 3 & $\mathrm{M}$ & $\mathrm{P}$ & $\mathrm{N}$ & 6 \\
\hline 35 & 90 & $\mathrm{G}$ & 3 & $\mathrm{P}$ & $\mathrm{P}$ & $\mathrm{N}$ & 3 \\
\hline 40 & 90 & $\mathrm{G}$ & 4 & $\mathrm{~T}$ & $\mathrm{P}$ & $\mathrm{N}$ & 4 \\
\hline 41 & 95 & $\mathrm{G}$ & 3 & $\mathrm{~T}$ & $\mathrm{P}$ & $\mathrm{N}$ & 2 \\
\hline 44 & 90 & $\mathrm{D}$ & 2 & $\mathrm{P}$ & $\mathrm{P}$ & $\mathrm{N}$ & 3 \\
\hline 46 & 90 & $\mathrm{D}$ & 2 & $M$ & $\mathrm{P}$ & $\mathrm{N}$ & 1 \\
\hline 48 & 90 & $\mathrm{G}$ & 4 & $\mathrm{~T}$ & $\mathrm{P}$ & $\mathrm{M}$ & 8 \\
\hline 49 & 90 & $\mathrm{D}$ & 4 & $\mathrm{M}$ & $\mathrm{P}$ & $\mathrm{N}$ & 4 \\
\hline 51 & 90 & $\mathrm{D}$ & 4 & $\mathrm{M}$ & $\mathrm{P}$ & $\mathrm{N}$ & 3 \\
\hline 53 & 90 & $\mathrm{D}$ & 3 & $\mathrm{P}$ & $\mathrm{P}$ & $\mathrm{N}$ & 1 \\
\hline 54 & 90 & $\mathrm{G}$ & 4 & $\mathrm{~T}$ & $\mathrm{P}$ & $\mathrm{C}$ & 3 \\
\hline 57 & 90 & $\mathrm{G}$ & 1 & $\mathrm{P}$ & $\mathrm{P}$ & $\mathrm{N}$ & 1 \\
\hline 59 & 90 & $\mathrm{~F}$ & 4 & $\mathrm{P}$ & $\mathrm{P}$ & $\mathrm{N}$ & 7 \\
\hline 60 & 90 & $\mathrm{D}$ & 1 & $\mathrm{P}$ & $\mathrm{P}$ & $\mathrm{N}$ & 3 \\
\hline 61 & 90 & $\mathrm{G}$ & 2 & $\mathrm{G}$ & $\mathrm{P}$ & $\mathrm{N}$ & 3 \\
\hline 62 & 90 & $\mathrm{G}$ & 1 & $\mathrm{G}$ & $\mathrm{P}$ & $\mathrm{N}$ & 1 \\
\hline 63 & 93 & $\mathrm{G}$ & 4 & $\mathrm{~T}$ & $\mathrm{P}$ & $\mathrm{N}$ & 9 \\
\hline 64 & 90 & $\mathrm{G}$ & 2 & $\mathrm{P}$ & $\mathrm{P}$ & $\mathrm{N}$ & 1 \\
\hline 65 & 90 & $\mathrm{G}$ & 2 & $\mathrm{G}$ & $\mathrm{P}$ & $\mathrm{C}$ & 1 \\
\hline 66 & 90 & $\mathrm{G}$ & 3 & $\mathrm{P}$ & $\mathrm{P}$ & $\mathrm{N}$ & 4 \\
\hline 68 & 90 & $\mathrm{D}$ & 4 & $\mathrm{M}$ & $\mathrm{P}$ & $\mathrm{N}$ & 1 \\
\hline 69 & 93 & $\mathrm{~F}$ & 4 & $\mathrm{~T}$ & $\mathrm{P}$ & $\mathrm{N}$ & 6 \\
\hline 70 & $93 / 95$ & $G$ & 4 & $\mathrm{~T}$ & $\mathrm{P}$ & $\mathrm{C}$ & 4 \\
\hline 71 & 90 & $\mathrm{G}$ & 3 & $\mathrm{~T}$ & $\mathrm{P}$ & $\mathrm{N}$ & 3 \\
\hline 73 & 93 & $\mathrm{G}$ & 3 & $\mathrm{G}$ & $\mathrm{P}$ & $\mathrm{N}$ & 2 \\
\hline
\end{tabular}




\begin{tabular}{|c|c|c|c|c|c|c|c|}
\hline Conjuntos & Campaña & Recogida & $\begin{array}{c}\text { Cantidad } \\
\text { Muestra }\end{array}$ & $\begin{array}{c}\text { Tamaño } \\
\text { Carbones }\end{array}$ & $\begin{array}{c}\text { Muestra } \\
\text { analizada }\end{array}$ & $\begin{array}{l}\text { Estado } \\
\text { Muestra }\end{array}$ & $\begin{array}{l}\mathrm{N}^{\circ} \mathrm{de} \\
\text { Taxones }\end{array}$ \\
\hline 74 & 93 & G & 4 & $\mathrm{G}$ & $\mathrm{P}$ & $\mathrm{N}$ & 1 \\
\hline 75 & 93 & $\mathrm{~F}$ & 4 & $\mathrm{~T}$ & $\mathrm{P}$ & $\mathrm{N}$ & 2 \\
\hline 76 & 93 & G & 1 & $\mathrm{P}$ & $\mathrm{T}$ & $\mathrm{N}$ & 2 \\
\hline 77 & 93 & $\mathrm{~F}$ & 2 & $\mathrm{P}$ & $\mathrm{P}$ & M & 2 \\
\hline 79 & 93 & G & 2 & $\mathrm{P}$ & $\mathrm{P}$ & $\mathrm{N}$ & 2 \\
\hline 80 & 93 & G & 1 & $\mathrm{P}$ & $\mathrm{T}$ & $\mathrm{N}$ & 2 \\
\hline 81 & 93 & $\mathrm{~F}$ & 4 & $\mathrm{~T}$ & $\mathrm{P}$ & $\mathrm{N}$ & 4 \\
\hline 82 & 93 & G & 1 & $\mathrm{P}$ & $\mathrm{T}$ & $\mathrm{N}$ & 1 \\
\hline 84 & 93 & G & 2 & $\mathrm{P}$ & $\mathrm{T}$ & $\mathrm{N}$ & 4 \\
\hline 86 & 90 & $\mathrm{~F}$ & 4 & $\mathrm{M}$ & $\mathrm{P}$ & $\mathrm{N}$ & 9 \\
\hline 87 & 93 & G & 3 & $\mathrm{M}$ & $\mathrm{P}$ & $\mathrm{N}$ & 1 \\
\hline 88 & 93 & G & 1 & $G$ & $\mathrm{~T}$ & $\mathrm{~N}$ & 1 \\
\hline 89 & 93 & G & 3 & $\mathrm{P}$ & $\mathrm{P}$ & $\mathrm{N}$ & 1 \\
\hline 90 & 93 & $\mathrm{G}$ & 4 & $\mathrm{~T}$ & $\mathrm{P}$ & $\mathrm{N}$ & 8 \\
\hline 91 & 95 & D & 1 & P & $\mathrm{T}$ & $\mathrm{N}$ & 1 \\
\hline 92 & 95 & D & 3 & $\mathrm{G}$ & $\mathrm{P}$ & $\mathrm{N}$ & 3 \\
\hline 93 & 95 & $\mathrm{G}$ & 4 & $\mathrm{M}$ & $\mathrm{P}$ & $\mathrm{N}$ & 4 \\
\hline 94 & 95 & D & 2 & $\mathrm{M}$ & $\mathrm{P}$ & $\mathrm{C}$ & 1 \\
\hline 95 & 95 & $\mathrm{D}$ & 2 & $\mathrm{P}$ & $\mathrm{P}$ & $\mathrm{N}$ & 2 \\
\hline 97 & 95 & G & 3 & $\mathrm{G}$ & $\mathrm{T}$ & $\mathrm{N}$ & 6 \\
\hline 98 & 95 & $\mathrm{D}$ & 3 & $\mathrm{G}$ & $\mathrm{P}$ & $\mathrm{N}$ & 3 \\
\hline 99 & 95 & G & 4 & $\mathrm{G}$ & $\mathrm{P}$ & $\mathrm{N}$ & 4 \\
\hline 100 & 95 & G & 4 & G & $\mathrm{P}$ & $\mathrm{N}$ & 1 \\
\hline 101 & 95 & $\mathrm{D}$ & 1 & $\mathrm{P}$ & $\mathrm{T}$ & $\mathrm{N}$ & 1 \\
\hline 102 & 95 & G & 4 & $\mathrm{~T}$ & $\mathrm{P}$ & $\mathrm{M}$ & 1 \\
\hline 103 & 95 & $\mathrm{G}$ & 2 & $\mathrm{~T}$ & $\mathrm{P}$ & $\mathrm{M}$ & 3 \\
\hline 104 & 95 & $\mathrm{P}$ & 3 & $\mathrm{~T}$ & $\mathrm{P}$ & $\mathrm{C}$ & 2 \\
\hline 105 & 95 & D & 2 & $\mathrm{G}$ & $\mathrm{T}$ & $\mathrm{N}$ & 4 \\
\hline 107 & 90 & $P$ & 3 & $P$ & $P$ & $\mathrm{~N}$ & 5 \\
\hline
\end{tabular}

- Campaña: del 90, 93 y 95.

- Método de Recogida: $\mathrm{F}=$ Flotación, $\mathrm{P}=\mathrm{Puntual}, \mathrm{G}=\mathrm{General,} \mathrm{D}=$ Desconocido.

- Cantidad de la Muestra: $1=$ entre 1 y 10, 2=10-50, 3=50-100 y el 4 más de 100 fragmentos.

- Tamaño de los carbones: Hace referencia al tamaño medio de los fragmentos de carbón comprendidos en cada muestra, así $\mathrm{P}=$ carbones menores de $0,5 \mathrm{~cm} ., \mathrm{M}=$ Medianos comprendidos entre 0,5 y $2 \mathrm{~cm}$., $G=$ Grandes mayores de $2 \mathrm{~cm}$. y T cuando hay de todos los tamaños.

- Muestra analizada: $\mathrm{P}=$ Parcial, $\mathrm{T}=$ Total.

- Estado de la Muestra: hace referencia al estado de conservación de los carbones. N=Normal, $\mathrm{C}=$ Muy carbonizados, donde existe un cierto grado de vitrificación que impide distinguir adecuadamente los elementos anatómicos, $\mathrm{M}=$ Malos.

- Número de Taxones: el número de taxones determinado en cada estructura. 


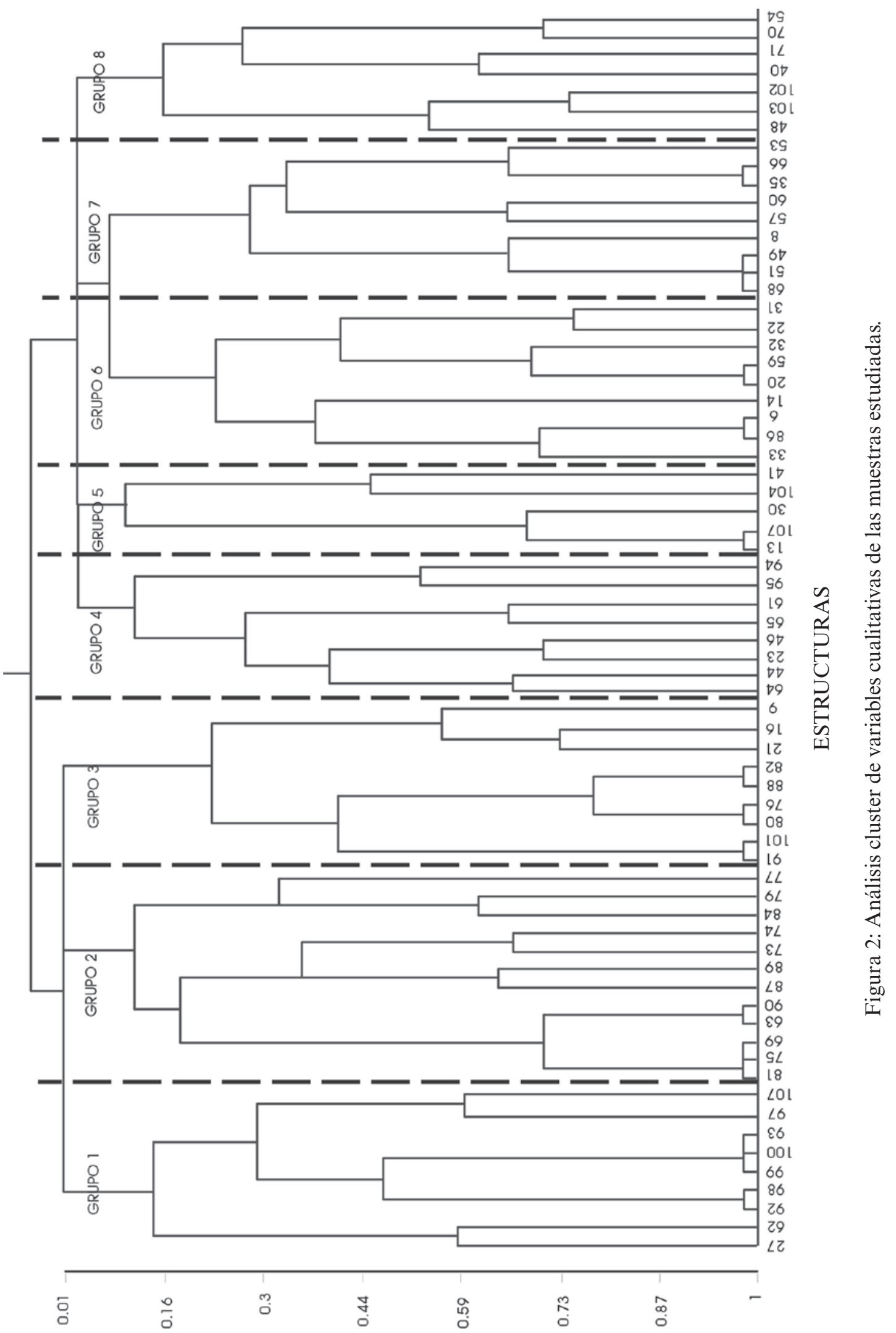


Todas estas variables con sus estados respectivos se han sometido a un análisis Cluster (Esquivel et al. 1991). El R-análisis agrupa a los quemaderos en función de las características de la muestra y del carbón recuperado. Así, observando el dendograma (Fig. 2) se pueden distinguir los siguientes grupos:

1. Se caracteriza por un estado normal de los carbones y un tamaño grande, presentando el resto de variables estados distintos.

2. Se caracteriza por un estado normal de los carbones. La recuperación ha sido general o por flotación, lo que está en relación con la gran cantidad de carbón recuperado y el estudio parcial de la muestra. Todas estas estructuras se excavaron en el 93 y presentan un número de taxones muy variable comprendido entre 1 y 9.

3. Este grupo coincide con estructuras con poco carbón recuperado, que se ha analizado en su totalidad. El resto de variables presentan múltiples estados pero el número de taxones es únicamente de 1 o 2 , es decir, la variabilidad de taxones es mínima.

4. Aquí la variable que condiciona el grupo es la cantidad media-baja de carbón recuperado (2) que ha sido parcialmente analizado. El resto de variables son independientes.

5. Al igual que el grupo anterior la cantidad de carbón recuperado es media (3) y está parcialmente analizado, siendo el resto de variables independientes.

6. Este grupo está condicionado por la recogida en flotación realizada en la Campaña de 1990, lo cual condiciona que exista una gran cantidad de carbón, estudiado parcialmente. Al igual que en el grupo 2 el número de taxones es muy variable y presenta valores entre 1 y 9.

7. Al igual que el grupo 2 el estado de los carbones es normal y han sido parcialmente estudiados, aunque todas las estructuras fueron excavadas en la Campaña de 1990. El resto de variables son independientes.

8. Este grupo se caracteriza por una recogida general del carbón y presentar carbones de todos los tamaños que han sido parcialmente estudiados. El resto de variables son independientes.

Como conclusión más relevante de este análisis Cluster podemos ver que el número de taxones es la variable que siempre se mantiene independiente, es decir, la aparición de las distintas especies vegetales en las estructuras no está condicionada por ninguna de las otras variables, por lo cual la aparición de una u otra especie en cada una de las estructuras no obedece a las incidencias propias de la combustión o de tipo postdeposicional (fragmentación diferencial, tamaño de los carbones, estado de la muestra), de extracción de la muestra (campaña, recogida y cantidad de la muestra) y de su estudio (número de carbones analizados). Esto posibilita el intentar descubrir si existen agrupaciones de taxones y si responden a conductas y funciones determinadas.

\section{III.2. La Paleoflora determinada}

En el antracoanálisis de las 68 estructuras o conjuntos arqueológicos analizados se han determinado un total de 19 taxa (Tabla 2). Estos presentan un grado de determinación variable que va desde la especie, género o familia a la agrupación bajo un taxón de dos o más especies con características anatómicas similares y difícilmente diferenciables. Seguidamente presentamos los taxa determinados con las características anatómicas y la ecología bajo la que se desarrollan.

ISSN: 1133-4525 ISSN-e: 2255-3924 
TABLA 2: Frecuencias absolutas de los taxones determinados en el antracoanálisis de las diversas estructuras de Cruz del Negro.

\begin{tabular}{|c|c|c|c|c|c|c|c|c|c|c|c|c|c|c|c|c|c|c|c|c|c|c|c|}
\hline CONJUNTOS & 6 & 8 & 9 & 13 & 14 & 16 & 20 & 21 & 22 & 23 & 27 & 30 & 31 & 32 & 33 & 35 & 40 & 41 & 44 & 46 & 48 & 49 & 51 \\
\hline \multicolumn{24}{|l|}{ Arbutus unedo } \\
\hline Cistus sp. & & & & & 4 & & 14 & & & & & & & & & & & & & & 1 & & \\
\hline Erica sp. & & & & & & & & & & & & & & & & & & & & & 5 & & \\
\hline Fraxinus sp. & & & & & & & 5 & & & & & & & & & & & & & & & & \\
\hline \multicolumn{24}{|l|}{ Leguminosas } \\
\hline Olea europaea & 20 & & 3 & 5 & 20 & & 1 & & 2 & 8 & & & 2 & 9 & 1 & 5 & 15 & 5 & 6 & 2 & 16 & 4 & 17 \\
\hline Phillyrea sp. & 1 & & & & & & 1 & & & & & & & & & 2 & & & & & 1 & & \\
\hline Pinus halepensis & & 1 & & & & & & & & 1 & & & & & & & & & 6 & & & & \\
\hline \multicolumn{24}{|l|}{ Pinus sp. } \\
\hline Pistacia lentiscus & 1 & 11 & & & 2 & 2 & 5 & & & 2 & 1 & 7 & 5 & & & & 4 & 1 & & & 8 & 11 & 2 \\
\hline Pistacia terebinthus & & 1 & & & & & & & & & & 2 & & & 2 & & & & & & & & \\
\hline Pistacia sp. & & & & & 3 & & & 3 & & & & & & & 2 & & 2 & & & & 1 & 2 & \\
\hline \multicolumn{24}{|l|}{ Populus sp. } \\
\hline Prunus sp. & & & & & & & & & & & & & & & & & & & 1 & & 2 & & \\
\hline Quercus ilex-coccifera & 12 & & & & 6 & & & & & & & & & & 8 & 1 & & & & & 8 & 1 & 2 \\
\hline Quercus suber & & & & & & & & & & & & & & & 1 & & 1 & & & & & & \\
\hline \multicolumn{24}{|l|}{ Quercus perennifolio } \\
\hline \multicolumn{24}{|l|}{ Quercus caducifolio } \\
\hline \multicolumn{24}{|l|}{ Vitis sp. } \\
\hline Indeterminadas & 1 & & & & & & 1 & & & & & & & & 1 & & & & & & & & \\
\hline Indeterminables & 3 & 1 & & & 3 & & 3 & 1 & 6 & 1 & & 2 & 3 & 1 & 3 & 2 & 3 & 4 & 1 & 5 & 8 & 2 & 4 \\
\hline $\begin{array}{l}\text { T. CARBONES } \\
\text { ANALIZADOS }\end{array}$ & 38 & 14 & 3 & 5 & 38 & 2 & 30 & 4 & 8 & 12 & 1 & 11 & 10 & 10 & 18 & 10 & 25 & 10 & 14 & 7 & 50 & 20 & 25 \\
\hline TOTAL TAXONES & 5 & 3 & 1 & 1 & 5 & 1 & 6 & 1 & 1 & 3 & 1 & 2 & 2 & 1 & 6 & 3 & 4 & 2 & 3 & 1 & 8 & 4 & 3 \\
\hline
\end{tabular}

\begin{tabular}{|l|c|c|c|c|c|c|c|c|c|c|c|c|c|c|c|c|c|c|c|c|c|c|c|}
\hline \multicolumn{1}{|c}{ CONJUNTOS } & 53 & 54 & 57 & 59 & 60 & 61 & 62 & 63 & 64 & 65 & 66 & 68 & 69 & 70 & 71 & 73 & 74 & 75 & 76 & 77 & 79 & 80 & 81 \\
\hline Arbutus unedo & & 8 & & & & & & & & & & & & & & & & & & & & & \\
\hline Cistus sp. & & & & 2 & & & & 2 & & & & & & & & & & & & & & & \\
\hline Erica sp. & & & & & & & 5 & & & & & 6 & & & & & & & & & & \\
\hline Fraxinus sp. & & & & 8 & & & & & & & & & & & & & & & & & & & \\
\hline Leguminosas & & & & & & & & & & & & & & & & & & & 1 & & & & \\
\hline Olea europaea & 10 & 17 & 3 & 5 & 2 & 3 & 3 & 1 & 1 & 8 & & 10 & & 65 & 4 & & 7 & 15 & & 1 & 9 & 4 & 21 \\
\hline Phillyrea sp. & & & & 1 & & & & 8 & & & 4 & & 2 & & & & & & & & & & \\
\hline Pinus halepensis & & & 2 & & & & & & & & & & & & & & 2 & & & & & 1 \\
\hline Pinus sp. & & & & & & & & & & & & & & & & & & & & & & 1 \\
\hline Pistacia lentiscus & & 3 & & 3 & & 3 & & 11 & & & & & 1 & 2 & 1 & & & & & & & & \\
\hline Pistacia terebinthus & & & & & & & & 5 & & & 3 & & 7 & 3 & 1 & & & & & & & & \\
\hline Pistacia sp. & & & & & & & 2 & & & 1 & & 9 & 1 & & 2 & & & & & & & \\
\hline Populus sp. & & & & & & & & & & & & & & & & & & & & & & \\
\hline Prunus sp. & & & & & & & & & & & & 5 & & & & & & & & & & \\
\hline Quercus ilex-coccifera & & & & & 1 & 2 & & & & & 6 & & & & & & & & 1 & 3 & 2 & 1 & 3 \\
\hline Quercus suber & & & & & & & & 2 & & & & & & & & 6 & & & & & & \\
\hline Quercus perennifolio & & & & 1 & & & & 4 & & & & & & & & & & & & & & \\
\hline Quercus caducifolio & & & & & 1 & & & & & & & & & & & & & & & & & \\
\hline Vitis sp. & & & & & & & & & & & & & & & & & & & & & & \\
\hline Indeterminadas & & & & & & & & & & & & & & & & & & & \\
\hline Indeterminables & & 9 & 6 & 4 & 1 & 2 & 4 & 2 & & & 4 & 2 & 7 & 2 & 1 & & 2 & & 2 & & \\
\hline $\begin{array}{l}\text { T. CARBONES } \\
\text { ANALIZADOS }\end{array}$ & 10 & 37 & 3 & 28 & 8 & 9 & 5 & 44 & 3 & 8 & 14 & 14 & 32 & 78 & 8 & 9 & 7 & 19 & 2 & 6 & 12 & 5 & 26 \\
\hline TOTAL TAXONES & 1 & 3 & 1 & 7 & 3 & 3 & 1 & 9 & 1 & 1 & 4 & 1 & 6 & 4 & 3 & 2 & 2 & 2 & 2 & 2 & 2 & 2 & 4 \\
\hline
\end{tabular}




\begin{tabular}{|c|c|c|c|c|c|c|c|c|c|c|c|c|c|c|c|c|c|c|c|c|c|c|c|}
\hline CONJUNTOS & 82 & 84 & 86 & 87 & 88 & 89 & 90 & 91 & 92 & 93 & 94 & 95 & 97 & 98 & 99 & 100 & 101 & 102 & 103 & 104 & 105 & 107 & $\mathrm{~N}^{\circ} \mathrm{E}$. \\
\hline Arbutus unedo & & & & & & & & & & & & & & & & & & & & & & & 1 \\
\hline Cistus sp. & & & 2 & & & & & & & & & & & & 13 & & & & 5 & & & 1 & 9 \\
\hline Erica $\mathrm{sp}$. & & & 1 & & & & & & & & & & & 3 & & & & & & 12 & & & 6 \\
\hline Fraxinus sp. & & 2 & & & & & 3 & & & & & & 7 & & & & & & & & 4 & & 6 \\
\hline Leguminosas & & & & & & & & & & & & & & & & & & & & & & 1 & 2 \\
\hline Olea europaea & & 12 & 1 & & & 7 & 27 & 1 & 9 & 8 & 10 & 6 & 2 & 7 & 1 & 5 & 1 & 25 & 3 & 1 & & 19 & 54 \\
\hline Phillyrea sp. & & & 5 & & & & & & & 3 & & & & 3 & 15 & & & & & & & & 12 \\
\hline Pinus halepensis & & & 2 & 5 & & & 4 & & & & & & 1 & & & & & & & & & & 10 \\
\hline Pinus sp. & 4 & & & & & & & & & & & & & & & & & & & & & & 3 \\
\hline Pistacia lentiscus & & & 4 & & & & 11 & & & 5 & & & 2 & & & & & & 3 & & 1 & 2 & 27 \\
\hline Pistacia terebinthus & & & 1 & & & & 1 & & & & & & & & & & & & & & & & 10 \\
\hline Pistacia sp. & & & & & 1 & & 2 & & 2 & 1 & & & & & & & & & & & & & 14 \\
\hline Populus sp. & & 1 & & & & & & & & & & & & & & & & & & & & & 1 \\
\hline Prunus sp. & & & & & & & & & & & & & & & & & & & & & & & 3 \\
\hline Quercus ilex-coccifera & & & & & & & 2 & & 4 & & & 1 & 9 & & & & & & & & 1 & 7 & 21 \\
\hline Quercus suber & & & 1 & & & & & & & & & & 1 & & 1 & & & & & & 3 & & 8 \\
\hline Quercus perennifolio & & & & & & & & & & & & & & & & & & & & & & & 2 \\
\hline Quercus caducifolio & & & & & & & & & & & & & & & & & & & & & & & 1 \\
\hline Vitis sp. & & 2 & & & & & & & & & & & & & & & & & & & & & 1 \\
\hline Indeterminadas & & & 1 & & & & 1 & & & & & & & & & & & & & & & & 5 \\
\hline Indeterminables & 1 & 3 & 5 & & & & 4 & & & & 1 & & 1 & 1 & 2 & & & & & 6 & 1 & 3 & 43 \\
\hline $\begin{array}{l}\text { T. CARBONES } \\
\text { ANALIZADOS }\end{array}$ & 5 & 20 & 23 & 5 & 1 & 7 & 55 & 1 & 15 & 17 & 11 & 7 & 23 & 14 & 32 & 5 & 1 & 25 & 11 & 19 & 10 & 33 & 1092 \\
\hline $\begin{array}{c}\text { TOTAL TAXONES/ } \\
\text { ESTRUCTURAS }\end{array}$ & 1 & 4 & 9 & 1 & 1 & 1 & 8 & 1 & 3 & 4 & 1 & 2 & 6 & 3 & 4 & 1 & 1 & 1 & 3 & 2 & 4 & 5 & $\begin{array}{l}19 / \\
68 \\
\end{array}$ \\
\hline
\end{tabular}

Arbutus unedo L. (madroño)

Familia: Ericaceae

\section{Anatomía:}

- Presenta una zona semiporosa en el leño temprano, de 30 a $40 \mu \mathrm{m}$. de diámetro. Por el resto del leño, las tráqueas están uniformemente repartidas con ordenación radial, algunas en grupos de 2 a 4, pero lo más frecuente es que vayan aisladas. El límite anual de crecimiento es bien visible.

- Los radios siempre heterogéneos, son uniseriados y pluriseriados, en este último caso, suelen tener 4 o 5 células de ancho. En altura oscilan entre 5 células los uniseries y 30 los pluriseries.

- Las traqueas presentan perforación simple y muy raras veces escalariforme y engrosamientos helicoidales muy juntos y marcados. Las punteaduras intervasculares son de talla media.

Ecología actual: se cría en los encinares, alcornocales y en los matorrales que resultan de su degradación, sobre todo tipo de terrenos, calcáreos o ácidos; aunque con un cierto grado de humedad y requiere un clima suave, sin fuertes heladas, por lo que, vive en los pisos termo y mesomediterráneo, no excediendo este último.

Cistus sp. (jaras) (Lám. I-4)

Familia: Cistaceae

Anatomía:

- Madera con porosidad dispersa, aunque en algunas especies presenta zona semiporosa. Vasos de pequeño tamaño, con diámetros entre 20 y $50 \mu \mathrm{m}$. 
- Las traqueas tienen perforación simple y presentan engrosamientos helicoidales muy finos en parte de algunos vasos. Las puntuaciones intervasculares son pequeñas, circulares y abundantes.

- Los radios son uniseriados o biseriados, heterogéneos.

Ecología actual: el género Cistus comprende una gran variedad de especies. Unas como el $C$. ladanifer se desarrolla sobre suelos silíceos, y otros como el C. albidus prefiere los ricos en cal. En general, forma parte de los matorrales y garrigas que sustituyen a los encinares degradados, en los pisos termo y mesomediterráneo.

\section{Erica sp. (brezos)}

Familia: Ericaceae

Anatomía:

- Madera de porosidad dispersa con las traqueas aisladas y ordenadas radialmente. Tienen un diámetro de 20 a $70 \mu \mathrm{m}$, generalmente de $40 \mu \mathrm{m}$. El parénquima es apotraqueal difuso.

- Las traqueas tienen perforación simple y punteaduras intervasculares finas. No tienen engrosamientos.

- Los radios son heterogéneos y de dos tipos: uniseriados de hasta 8 células de altura y multiseriados de 4 a 5 de anchura y hasta 20 de altura.

Ecología actual: el género comprende varias especies con ecología diferente, aunque en general, forma parte de los bosques aclarados: matorrales, espartales y encinares. Algunas especies prefieren los terrenos calizos (E. multiflora) y otras los silíceos (E. scoparia y arborea).

Fraxinus sp. (Fresnos) (Lám. II-3)

\section{Familia: Oleaceae}

\section{Anatomía:}

- Madera con zona porosa. Los vasos de la madera inicial están solos o juntos en grupos de 1 a 4 ordenados radialmente. El diámetro de los vasos varia en las distintas especies, pero siempre los de la zona porosa son mucho mayores que los de la madera final. La relación $\mathrm{P} / \mathrm{p}$ (donde $\mathrm{P}$ es el diámetro de los vasos del leño inicial y p es el de los vasos del leño final) permite distinguir varias especies: el Fraxinus ornus presenta una relación de 4/1; el F. excelsior de $8 / 1$; y el F. oxycarpa de 6/1. Las muestras que nosotros hemos observados pertenecen por lo general al Fraxinus ornus.

- El parénquima es muy abundante, paratraqueal vasicéntrico y terminal.

- Las traqueas tienen perforación simple y punteaduras intervasculares muy numerosas. No tiene engrosamientos.

- La anchura de los radios varia en algunas especies: de 1 a 5 en el F. excelsior, de 3 a 4 en el $F$. oxycarpa y de 1 a 2 en el $F$. ornus. Tienen de 10 a 16 célula se alto y son homogéneos o heterogéneos del tipo III.

Ecología actual: el fresno es un árbol que crece en el borde de los ríos y en los fondos de los valles con suelos frescos y nivel fréatico elevado. A veces también en los bosques frescos y umbrosos. El Fraxinus ornus tiene una repartición actual muy localizada en las montañas de Levante, mientras que el $F$. angustifolia es más frecuente en el Sur. Pertenecen al piso de vegetación meso o supramediterráneo, aunque el primero puede bajar al termo. 


\section{Leguminosae (Leguminosas)}

\section{Anatomía:}

La madera de la familia de las Leguminosas tiene estructura anatómica muy parecida por lo que se hace muy difícil su identificación en géneros y especies. Sus características generales son:

- Madera de poros en anillo. Las tráqueas están agrupadas en filas radiales sinuosas con un diámetro entre 30 y $60 \mu \mathrm{m}$.

- Los vasos tienen perforación simple, engrosamientos helicoidales y punteaduras intervasculares vestidas; es decir, una membrana que recubre la abertura.

- Los radios son heterogéneos, generalmente de 1 a 3 células de anchura aunque llegan a veces a 8 células y con más de 20 células de altura.

- Muchos de todos los elementos anatómicos están estratificados, característica de toda la familia.

Ecología actual: en general, las especies leñosas de Leguminosas de nuestra zona se desarrollan en los piornales y matorrales que ocupan los calveros de los bosques, montes desforestados y aun en las vaguadas y laderas secas y soleadas; según la especies pueden preferir terrenos con cal o sin ella (silíceos) y vivir en el piso inferior térmico y montañas cálidas o ascender hasta las cumbres de las montañas, sometidas a fríos intensos.

Olea europaea L. (acebuche y olivo) (Lám. II-1).

Familia: Oleaceae

Anatomía:

- Madera homogénea con porosidad dispersa. Las tráqueas van aisladas o asociadas de 2 a 5 . Su diámetro es de $80 \mu \mathrm{m}$. en el leño temprano disminuyendo a $20 \mu \mathrm{m}$. en el tardío.

- El parénquima es apotraqueal vasicéntrico y bastante abundante. Las fibras tienen paredes gruesas.

- Tráqueas con perforación simple y punteaduras intervasculares finas y muy abundantes.

— Los radios son biseriados o triseriados, de altura alrededor de 10 células; muy heterogéneos.

Aunque se han hecho algunos intentos para la distinción anatómica de las las dos subespecies en base a la densidad de vasos (Terral 1996; Terral y Arnold-Simard 1996), su distinción resulta casi imposible de realizar.

Ecología actual: el acebuche acompaña a las encinas, quejigos, y alcornoques o en los matorrales que resultan de su degradación, junto al lentisco, mirto, palmito y espino negro. Vive en todo tipo de suelos y aguanta bien el calor, pero es sensible al frío, especialmente a las heladas, por lo que sólo vive, de forma natural, en el piso termomediterráneo.

Phillyrea sp. (Labiérnago)

Familia: Oleaceae

Anatomía:

- Madera con vasos en disposición radial oblicua en forma de flama.

- El parénquima es paratraqueal y apotraqueal disperso.

- Los vasos tienen perforación simple y engrosamientos helicoidales, al igual que las fibrotraqueidas.

— Los radios son uniseriados y biseriados de 8 a 20 células de altura, heterogéneos del tipo I y II. Las células de los radios son grandes y redondas.

La Phillyrea latifolia tiene, por lo general, radios biseriados. 
Ecología actual: dos especies pueden ser encontradas en nuestra región: la P. angustifolia vive en el piso termomediterráneo en ambiente de encinar o alcornocal, mientras que la $P$. latifolia que se desarrolla en los encinares y otros bosques de hoja esclerófila y perenne, así como en los matorrales que resultan de su destrucción; muchas veces entre rocas o en suelos pedregosos, puede ascender al piso mesomediterráneo. Siendo indiferente al tipo de suelo.

Pinus halepensis Miller (pino carrasco) (Lám. II-2)

Familia: Pinaceae

Anatomía:

- Tiene canales resiníferos repartidos por todo el anillo de crecimiento, sin una zona de preferencia. El diámetro de estos oscila entre 100-200 $\mu \mathrm{m}$. Los canales horizontales son más pequeños y se localizan en algunos radios.

- Los radios son uniseries de 1 a 10 células de alto.

- Las traqueidas presentan punteaduras areoladas grandes y uniseriadas sobre las paredes radiales de la madera final. Las traqueidas horizontales son numerosas y no están dentadas.

- En los campos de cruce tienen de 1 a 4 punteaduras del tipo pinoide.

Ecología actual: se desarrolla en las colinas y laderas secas soleadas, desde el nivel del mar hasta cerca de los $1.000 \mathrm{~m}$., subiendo hasta los $1.600 \mathrm{~m}$. en algunas sierras andaluzas. Prefiere los suelos ricos en cal y es el pino más resistente a la sequía, manteniéndose a veces con sólo $300 \mathrm{~mm}$. anuales; se adapta a los suelos pobres y esqueléticos, soportando bien una cierta cantidad de yeso. Puede vivir en el piso de vegetación termo- o mesomediterráneo.

Pistacia lentiscus L. (lentisco) y

Pistacia terebinthus L. (cornicabra) (Láms. I-5 y 6)

Familia: Anacardiaceae

Anatomía:

- Madera con zona semiporosa o porosidad semicircular en el leño temprano. A partir de aquí salen grupos de tráqueas o tráqueas solas más pequeñas con disposición radial. El diámetro de los vasos o tráqueas nos permite distinguir las dos especies: la zona porosa del lentisco $(P$. lentiscus) presenta los vasos más pequeños (hasta $70 \mu \mathrm{m}$ ); mientras que los de la cornicabra o terebinto ( $P$. terebinthus) sobrepasan los $80 \mu \mathrm{m}$.

- El parénquima es apotraqueal difuso y paratraqueal vasicéntrico.

- Los vasos tienen perforación simple, engrosamientos helicoidales y punteaduras intervasculares.

- Radios heterogéneos, uni- o biseriados de 7 a 30 células de altura en la P. lentiscus y de 1 a 3 células de ancho en la $P$. terebinthus. A veces se pueden observar canales secretores en los radios.

- Tienen células cristalíferas en algunas fibras y en el parénquima.

Ecología actual: el lentisco se desarrolla en los matorrales y garrigas desarrolladas en ambiente de encinar, sobre todo tipo de suelos, asociándose a mirtos, coscojas, palmitos, aladiernas, etc., en las asociaciones del piso termo y mesomediterráneo inferior. Resiste mal las heladas. El terebinto o cornicabra es más resistente al frío que el anterior, por lo que sube hasta cerca de los $1.500 \mathrm{~m}$.

Populus sp. (álamos) (Lám. II-4)

Familia: Salicaceae

Anatomía:

- Madera con tráqueas extendidas por todo el anillo, solas o en grupos de 2 a 5 y en disposición radial. Los traqueas tienen sección circular o poligonal irregular, con diámetro entre 50 y $100 \mu \mathrm{m}$. ,que disminuye un poco en el leño tardío. 
- Los vasos tienen perforación simple y puntuaciones intervasculares bastante grandes.

- Las puntuaciones del campo de cruce son grandes.

- Los radios son uniseriados, muy raramente biseriados, de 5 a 30 células de altura y homogéneos.

Ecología actual: se cría en los suelos frescos y húmedos. Forma parte de los sotos y bosques ribereños.

Prunus sp. (Prunoidéas: almendro, ciruelo, cerezo, endrino, ...)

Familia: Rosaceae

El género Prunus engloba entre sus especies a la gran mayoría de árboles frutales de la familia de las rosáceas: cerezos, albaricoques, ciruelos, etc., aunque también se engloban especies silvestres, como el Prunus spinosa (endrino) o el Prunus mahaleb (cerezo de Santa Lucía). Su anatomía es muy similar y sólo en caso de muestras en buen estado es posible su determinación específica. No descartamos que los fragmentos analizados en Cruz del Negro puedan pertenecer al Prunus amygdalus o almendro.

Anatomía:

- Madera con porosidad difusa o con zona semiporosa poco marcada. Los vasos tienen ordenación radial, solos o en grupos de 2-6. Su diámetro es de $70 \mu \mathrm{m}$. En el leño de primavera, disminuyendo hasta $20 \mu \mathrm{m}$. en el de invierno. Tiene parénquima apotraqueal difuso.

- Los vasos tienen perforación simple y engrosamientos helicoidales.

- Los radios son heterogéneos y, en todas las especies, son de dos tipos: uniseriados y multiseriados; estos últimos con una anchura entre 3 y 10 células y 10-30 de altura.

Ecología actual: algunas especies silvestres como Prunus spinosa y Prunus mahaleb forman parte de las orlas espinosas de los quejigares y robledales. El almendro cultivado es una especie esencialmente termomediterránea, que se ha considerado tradicionalmente como introducida de Oriente. Sin embargo, frecuentemente se le encuentra en los niveles del Tardiglaciar en yacimientos arqueológicos del Mediterráneo Occidental.

Quercus sp.

Familia: Fagaceae

Dentro de los Quercus se han distinguido: los Quercus de hoja caduca y los de hoja perenne en los que hemos distinguido los del tipo ilex-coccifera y el $Q$. suber.

\section{Quercus caducifolios (robles)}

La distinción entre las diferentes especies de Quercus de hoja caduca es difícil, esto se agrava por la gran facilidad de hibridación de estos árboles. La aparición de un sólo fragmento determinado y el mal estado de conservación del mismo nos impide determinar la especie, aunque con toda probabilidad sea Quercus faginea o quejigo.

Anatomía:

- Madera con poros en anillo. En general, se dispone una sola línea de vasos en la madera inicial con diámetros que oscilan entre las 160 y $300 \mu \mathrm{m}$. En el leño tardío los vasos más pequeños con diámetros de 40-60 $\mu \mathrm{m}$. Esto establece una relación $\mathrm{P} / \mathrm{p}=3 / 1$.

- El parénquima es apotraqueal difuso, formando bandas.

- Traqueas con perforación simple y puntuaciones intervasculares bastantes grandes.

— Los radios son uniseries y multiseries, todos homogéneos. Los multiseriados tienen de 70 a $154 \mu \mathrm{m}$. de ancho. 
Ecología actual: se cría en todo tipo de suelos, tanto en los pobres como en los ricos en cal, aguantando muy bien en algunas de sus variedades los climas continentales, con fuertes contrastes de temperatura y humedad; puede ascender en el sur hasta cerca de los $1.900 \mathrm{~m}$ y requiere unas condiciones parecidas a las de la encina, aunque necesita suelos algo más frescos y profundos. Pertenece al piso de vegetación supramediterráneo o al mesomediterráneo superior. Por lo que su aparición en Carmona puede significar que estaba refugiado en zonas de umbría o cerca de cursos de agua.

Quercus ilex L y Quercus coccifera L (encina y coscoja) (Lám. I-3)

Anatomía:

- Madera con porosidad extendida. El diámetro de las traqueas en el leño temprano es de $104 \mu \mathrm{m}$. como media, no sobrepasando las $150 \mu \mathrm{m}$. En el leño tardío es de $30 \mu \mathrm{m}$. Relación $\mathrm{P} / \mathrm{p}=3 / 1$.

- El parénquima es apotraqueal difuso, formando bandas.

- Los vasos tienen perforación simple y punteaduras intervasculares grandes.

- Los radios son de dos tipos: uniseriados de 10 células de alto como media; y multiseriados que llegan a alcanzan más de $800 \mu \mathrm{m}$. de ancho, homogéneos.

Saint-Laurent (1926) llega a distinguir anatómicamente el Q. ilex del Q. coccifera, basandose en la anchura y distribución de los radios. Para el Quercus ilex da como ancho máximo de los radios $1.000 \mu \mathrm{m}$. y se localizan bastante juntos a una distancia media de $1.500 \mu \mathrm{m}$. Para el Quercus coccifera dice que los radios son más estrechos, $300 \mu \mathrm{m}$., y están más separados, a una media de $1.700 \mathrm{a}$ $2.350 \mu \mathrm{m}$.

Ecología actual: la encina se desarrolla en todo tipo de suelos, desde el nivel del mar hasta unos 1.400 m.; adaptada a soportar fuertes sequías estivales y los climas duros continentales, es el árbol dominante en gran parte de las regiones de clima mediterráneo seco. Vive preferentemente en el piso mesomediterráneo pero tanto desciende al termo como sube al supramediterráneo.

La coscoja forma parte importante de los matorrales altos que sustituyen a los encinares quemados, talados o degradados, a los que muchas veces da nombre (coscojares, garrigas); es indiferente a la naturaleza química del suelo y amante de climas cálidos, soportando muy bien las sequías estivales. Vive principalmente en el termomediterráneo, aunque también la encontramos en el mesomediterráneo, en exposiciones térmicas.

Quercus suber L. (alcornoque) (Láms. I-1 y 2)

Anatomía:

La distinción del alcornoque es en muchas ocasiones problemática, pues los caracteres anatómicos del $Q$. Suber son igual que los de la encina o coscoja, sólo se diferencian en la talla y disposición de los vasos.

En general, los vasos del alcornoque tienen un diámetro entre 200 y $250 \mu \mathrm{m}$., y se reparten por todo el anillo de crecimiento, sin formar flamas como en el caso del Q. ilex-coccifera. También es de tener en cuenta la abundancia de parénquima paratraqueal y apotraqueal en bandas.

Ecología actual: se desarrolla en suelos desprovistos de cal y en climas suavizados por la influencia del mar, algo húmedos y sin fuertes heladas, por lo que prefiere las laderas poco elevadas, abrigadas de los vientos del norte, desde el nivel del mar a poco más de $1.000 \mathrm{~m}$. Vive en los pisos termo y mesomediterráneo. 
Vitis sp. (vid) (Láms. II-5 y 6)

Familia: Vitaceae

Anatomía:

- Madera con zona porosa. Los vasos de la madera final presentan una disposición agrupada, siendo mucho más pequeños que los de la madera inicial.

- Las traqueas tienen engrosamientos helicoidales, perforaciones simples y escalariformes y puntuaciones con tendencia escalariforme.

- Los radios son muy anchos (hasta 20 células) y muy altos. Heterogéneos del tipo I y II.

Ecología actual: ningún carácter anatómico permite distinguir la viña silvestre de la cultivada. En estado silvestre, la viña forma parte del bosque de ribera de zonas templadas.

\section{III.3. Análisis cualitativo de los taxones}

Se han sometido los resultados obtenidos por el antracoanálisis (Tabla 2 ) a un Análisis Cluster utilizando variables cualitativas (Esquivel et. al. 1991), en un primer momento codificados en tablas de presencia/ausencia. Se ha obtenido el dendograma R-análisis, agrupa a los conjuntos o quemaderos en función de los taxones que aparecen en ellos (Fig. 3)

Así, observando el dendograma R-análisis se pueden distinguir varios grupos de quemaderos, unidos en función de la aparición en ellos de determinados taxones (Fig. 3) que pasamos a describir:

Grupo 1: Este grupo está definido por la aparición de la encina o coscoja, presentandose en cuatro quemaderos $(77,79,80$ y 95) en asociación con el acebuche. La mayoría de las estructuras de este grupo se sitúan en la zona Suroeste del área excavada, predominando las de tamaño pequeño (Fig. 4).

Grupo 2: el taxón que aparece en las cuatro estructuras de este grupo son los brezos, los cuales en dos casos (69 y 48) están junto a un número importante de especies, 6 y 8 respectivamente, indicando una asociación vegetal de encinar termomediterráneo. A nivel espacial 3 de las 4 estructuras se sitúan en la zona Sureste.

Grupo 3: el taxón que define este grupo son las jaras, apareciendo en la mayoría de los casos junto con un gran número de especies (de 3 a 9). La asociación más usual es con el acebuche (todas las estructuras) y el lentisco ( 6 de las 7 estructuras), apareciendo también los labiérnagos ( 5 de las 7), con lo cual se define una asociación vegetal de tipo termomediterráneo dominada por las especies arbustivas y de matorral. A nivel espacial 5 de las 7 estructuras se distribuyen por la parte norte o superior del área excavada (Fig. 3), mientras que las estructuras 99 y 103 aparecen juntas en el sector SE.

Grupo 4: viene claramente definido por los quemaderos o sepulturas donde sólo ha aparecido el acebuche (18 casos) o en asociación con el lentisco (2) y con este y el madroño (quemadero 54). Aparecen por todo la área excavada.

Grupo 5: en este caso es el lentisco la especie que aparece sola o bien en asociación con la cornicabra. Se distribuyen por toda la área y destaca la proximidad de las estructuras 70 y 71 .

Grupo 6: en este grupo es el pino carrasco el que aparece en las 6 estructuras, en dos casos sólo $\left(n^{\circ} 82\right.$ y 87 ) y en el resto junto al acebuche y otras especies. A nivel espacial destaca la proximidad de las estructuras 81,82 y 75 .

Grupo 7: el taxón que define este grupo son los fresnos, en un caso (84) en asociación con otras especies de ribera como son los álamos y, posiblemente la vid silvestre, y en los otros dos casos en asociación con la encina-coscoja, los pinos y el alcornoque, asociación que denota un ambiente 


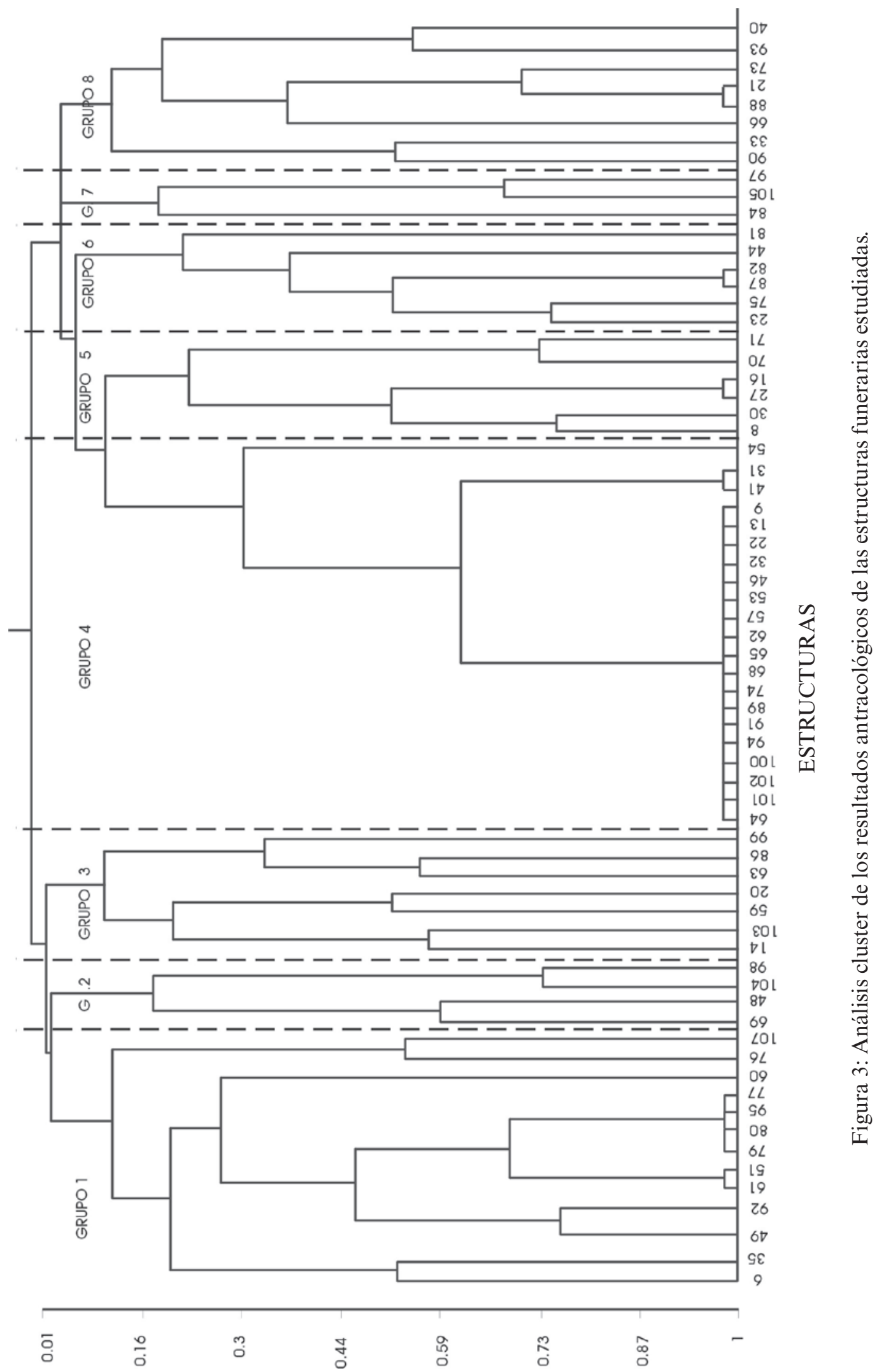




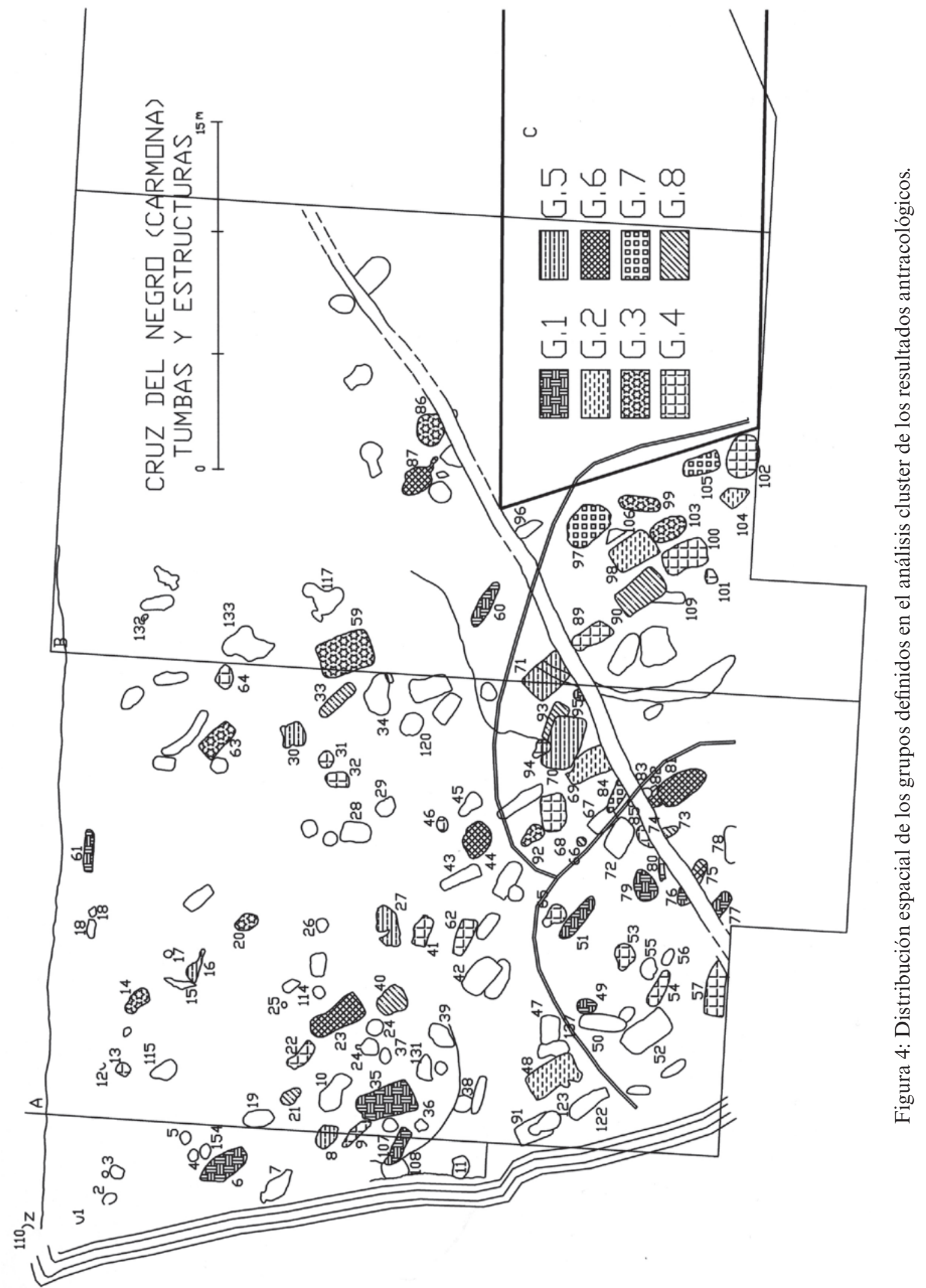


forestal y relativamente húmedo, pudiendo indicar un área de recogida concreta, posiblemente entorno a un cauce de agua. Estas estructuras aparecen en el sector SE del área excavada.

Grupo 8: el taxón que aparece en todas las estructuras de este grupo es la Pistacia, género que engloba tanto al lentisco como a la cornicabra y que se denomina así cuando el estado del carbón no permite la identificación específica de estas especies. Se distribuyen por toda la área excavada.

Por tanto, el análisis Cluster nos define una serie de grupos de estructuras en función de la aparición de taxones específicos en asociación con el resto de especies vegetales. Varios de estos grupos nos definen:

a). Conjuntos de estructuras que han utilizado las mismas especies vegetales como combustible para realizar la cremación de los cadáveres o ritos funerarios.

b). Asociaciones vegetales que pueden tener una distribución diferenciada en el entorno de la necrópolis. Por tanto, algunos de estos grupos nos podrían indicar lugares de recogida de leña diferenciados, utilizándose la vegetación de las distintas áreas en distintos momentos o por la realización de ritos específicos con el empleo de ciertas especies vegetales, como es el caso del pino carrasco y del que hablaremos posteriormente.

c). A nivel espacial zonas de la necrópolis caracterizadas por la aparición de varios de estos grupos:

- zona suroeste: en la que predominan los grupos 1 y 6 (aparte del 4 que está por todo el área).

- zona sureste: caracterizada por la presencia del resto de grupos, generalmente presentando un apareamiento de estructuras:

grupo 2: estructuras 98-104,

grupo 3: 99-103,

grupo 5: 70-71,

grupo 7: 97-105.

grupo 8: 90-93

las cuales podrían indicar una contemporaneidad de estas, o la realización próxima en el tiempo, además de lo señalado en los dos puntos anteriores.

\section{IV.VALORACIÓN Y DISCUSIÓN}

\section{IV.1. Una valoración paleoetnobotánica de los resultados}

Los grupos definidos en el dendo-grama (Fig. 3) no se agrupan en todos los casos en torno a los taxones mayores, es decir, a los que aparecen en mayor número de estructuras, como es el caso de la Phillyrea que ocupa el quinto puesto en frecuencia de aparición. Por tanto, creemos interesante realizar un repaso de los distintos taxones determinados en el antracoanálisis, para obtener informaciones complementarias que nos completen la visión de conjunto de las estructuras analizadas.

El taxón que aparece en mayor número de conjuntos es la Olea europaea, que aparece en 55 de 68, constituyéndose en la especie más utilizada dentro de la necrópolis, apareciendo como única especie en 18. La determinación anatómica entre la variedad cultivada, el olivo, y la variedad silvestre, el acebuche (Olea europaea var. sylvestris Brot.) es muy difícil, máxime cuando la mayoría de las muestras de este yacimiento muestran una gran deformación debida a las altas temperaturas alcanzadas que hacen que los carbones estén un poco vitrificados, estando todos sus elementos anatómicos hechos un bloque (Lám. I-1). 


\section{CONJUNTO LXX}

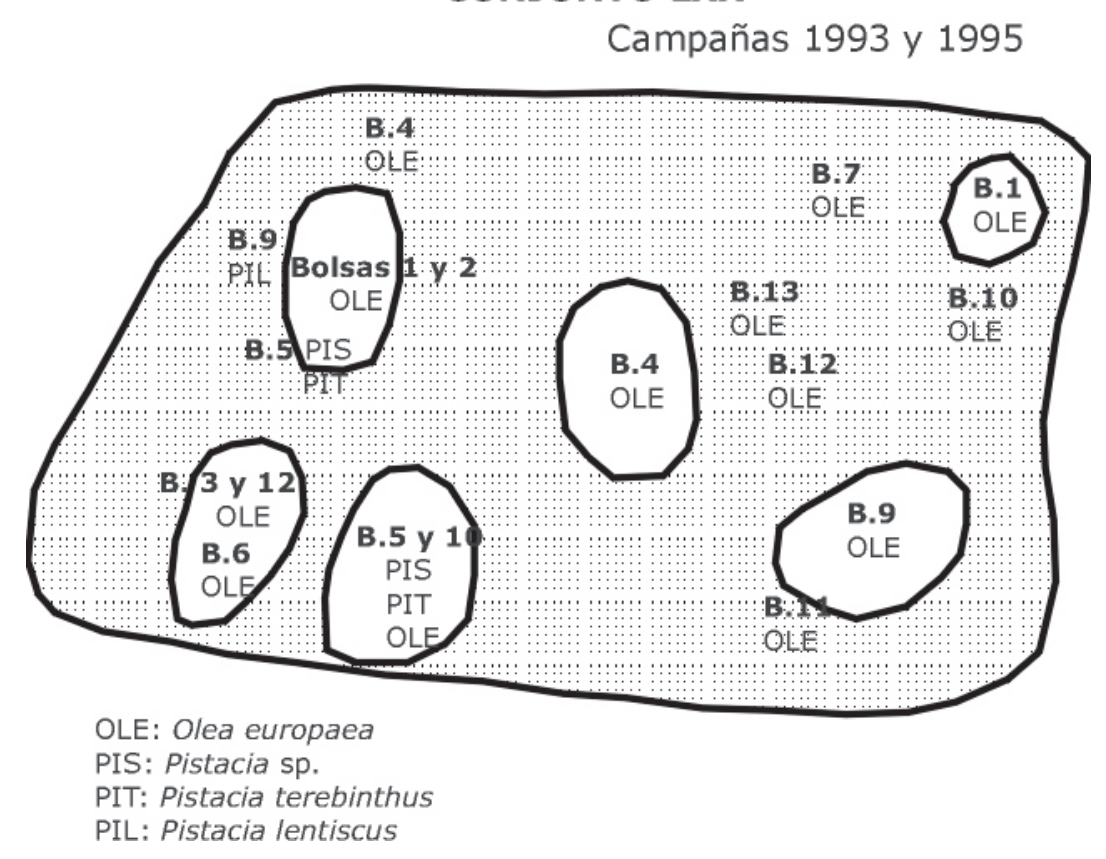

Figura 5: Distribución espacial de los taxones determinados en el antracoanálisis del Conjunto LXX.

La Olea, al ser el taxón más frecuente, aparece asociado a casi todo el resto de taxones determinados, indicando, por un lado, la preferencia como combustible de esta especie y, por otro, posiblemente, que era muy abundante en su entorno. La asociación principal de la Olea es con el lentisco, segundo taxón más frecuente, lo cual abogaría por la existencia de estas especies en un mismo medio ecológico, indicando su procedencia de las zonas con vegetación natural.

En tres conjuntos con la asociación Olea-lentisco disponemos de la ubicación espacial de las muestras antracológicas dentro de las estructuras de combustión. En el Conjunto LXX los fragmentos de Olea aparecen en casi todas las muestras y dispersos por toda la superficie, mientras que el lentisco aparece en dos muestras situadas a un lado de la estructura (Fig. 5), lo que podría indicar que esta última especie se utilizó como mecha para el inicio de la combustión, mientras que la Olea era la leña principal utilizada para la cremación del cadáver.

El tercer taxón en frecuencia de aparición es la encina y/o coscoja presente en 21 quemaderos. En 18 de estos 21 aparece en asociación con la Olea, lo que nos hablaría de la asimilación de la encina con el acebuche por tener unas parecidas características en cuanto a poder calorífico (Elvira y Hernando 1989) y durabilidad. Sustituye completamente a la Olea en 3 ocasiones, en las cuales aparece mayoritariamente en asociación con arbustos como el lentisco, los labiérnagos y las leguminosas arbustivas, todos ellos pertenecientes al estrato arbustivo de los encinares meso-termomediterráneos. En necrópolis de incineración de la II Edad del Hierro en Francia se ha documentado la elección de ramas de encina y de robles, elegidas, posiblemente, por su calibre medio más fácil de transportar, pero también por la presencia de hojas que hacen aumentar el poder calorífico de estas especies (Chabal 1995).

Como hemos indicado anteriormente, la Phillyrea es el quinto taxón con mayor presencia en número de estructuras. Éste género puede englobar a dos especies en esta región: la $P$. angustifolia (labiérnago u olivilla) y la $P$. latifolia (labiérnago o agracejo) que se desarrollan en el sotobosque de los encinares o alcornocales. En general, los labiérnagos aparecen en las estructuras con mayor 
número de taxones, y las asociaciones con jaras (en 6 estructuras), encina (4) y brezos (4) indican que estas especies formaban parte de los matorrales del encinar y que siempre fueron cogidos en unión de estas especies, como parte integrante de la leña menuda o mecha de la pira crematoria. Por tanto, estas especies no eran buscadas por si mismas, sino como parte integrante de los matorrales, especialmente los jarales y los brezales.

El sexto taxón con mayor presencia en número de estructuras es el pino carrasco, el cual aparece como único taxón en dos quemaderos ( 82 y 87) y en asociación con 4 o más taxones en cuatro (81, 86, 90 y 97). En estos aparecen otros árboles como la encina, el alcornoque y los fresnos; arbustos como el lentisco y los labiérnagos y matorral fruticoso como los brezos y las jaras. Tres de estas estructuras $(81,90$ y 97) son de gran tamaño dentro del conjunto excavado, lo cual nos hace pensar que el pino carrasco se pudo utilizar para formar un emparrillado sobre el que se colocará al difunto, sirviendo el resto de especies como combustibles para la cremación. También podría indicar, al aparecer en asociación con otras especies (encina, acebuche y alcornoque), que su presencia en el entorno no era muy frecuente. Así, como su asociación en los quemaderos con especies desarrolladas sobre sustratos básicos y silíceos no indica un lugar concreto de recogida, aunque también podría hablarnos de una cierta degradación de los encinares basófilos, por lo que hay que recurrir a una multiplicidad de medios para recoger la leña necesaria.

La cornicabra (Pistacia terebinthus) aparece en 10 estructuras, situándose junto al pino carrasco en el sexto lugar de aparición. En ocho ocasiones aparece en asociación con el lentisco, mientras que en las otras dos estructuras ( $\mathrm{n}^{\circ} .33$ y 66 ) englobadas en el grupo 8 del análisis Cluster, definido por la aparición de la Pistacia sp., aparece con la encina/coscoja, lo cual nos indica una asociación típica mesomediterránea de encinar, expresando una zona de recogida de leña específica.

Las jaras con la presencia en 9 estructuras es otro de los taxones que definen el grupo 3. Éstas, al igual que los labiérnagos, siempre aparecen junto a un gran número de especies de los matorrales termo-mesomediterráneos.

El alcornoque y los brezos ocupan el octavo y noveno puesto respectivamente. En dos ocasiones aparecen en las mismas estructuras $\left(\mathrm{n}^{\circ} 63\right.$ y 86 ) junto a un gran número de taxones (9), pero no aparece la encina y la presencia de la Olea es de sólo un fragmento, indicando que la leña utilizada proviene, posiblemente, de un rodal con sustrato silíceo, donde predominan los brezos y jaras pringosas, especies de los matorrales del alcornocal.

Otra de las asociaciones significativas del alcornoque es con los fresnos, los cuales aparecen juntos en dos ocasiones (97 y 105), pudiendo indicar el desarrollo del alcornoque cerca de los cursos de agua o suelos frescos. Los fresnos, en otro caso (84) aparecen junto al álamo, acebuche y vid, lo que indica una recogida de leña en torno a un río o arroyo y el posible origen silvestre de los 2 fragmentos de vid identificados, pues la variedad silvestre de esta especie forma parte de la ripisilva de la zona, principalmente formando parte de la asociación Viti viniferae-Salicetum atricine real (Asensi y Díez 1987:223). Aunque por su anatomía (Lám. I-5 y 6) no podamos descartar el origen cultivado de estos fragmentos, y en otros yacimientos de Andalucía Occidental su aparición en los diagramas antracológicos coincida en el tiempo con la Cruz del Negro (Rodríguez-Ariza, Aguayo y Moreno 1992), su aparición junto a especies de la ripisilva ha de plantearnos la duda de su origen silvestre o cultivado.

\section{IV.2. Una valoración paleoecológica de los resultados obtenidos}

Se han determinado un total de 19 taxa, de los cuales si no tenemos en cuenta Pistacia sp. y Pinus sp., que podrían corresponderse con Pistacia lentiscus y Pistacia terebinthus el primero, y con 
Pinus halepensis el segundo, nos queda un total de 17 taxa, cifra considerable si tenemos en cuenta que los carbones provienen de conjuntos cerrados y lo comparamos con otros estudios antracológicos realizados en necrópolis de incineración (Grau 1993). Esta lista floral pone de relieve la existencia de varios medios ecológicos entorno al yacimiento:

- una vegetación de ribera que crecería entorno a los arroyos o torrentes, representada por los fresnos, álamos y, posiblemente, la vid silvestre.

- una vegetación sobre sustratos básicos, caracterizada por el desarrollo importante de las especies arbustivas como acebuches, lentiscos, jaras y labiérnagos que con la presencia de la encina y/o coscoja nos indica que estamos en una etapa de degradación de carrascales o encinares termomediterráneos, posiblemente de la asociación del Oleo-Querceto rotundifoliae.

- una vegetación sobre sustratos silíceos, representada principalmente por el alcornoque y los brezos. Aunque, sobre sustratos arenosos y ombroclima seco la serie del alcornocal (OleoQuerceto suberis) puede encontrar refugio cerca de la vegetación de ribera.

- cultivos, representados por los Prunus sp. que parecen corresponderse con los almendros (Prunus cf. amygdalus).

Por tanto, podemos pensar que en esta época aún se conservan amplias zonas con vegetación natural que permiten el desarrollo de especies vegetales que parecen denotar unos parámetros bioclimáticos muy parecidos a los actuales, aunque quizás con un poco más de humedad, posiblemente un ombroclima subhúmedo frente al seco actual.

\section{BIBLIOGRAFÍA:}

ASENSI, A. y DÍEZ GARRETAS, B. (1987): “Andalucía Occidental” en M. PEINADO LORCA y S. RIVAS-MARTÍNEZ: La Vegetación de España: 197-230. Alcalá de Henares.

CHABAL, L. (1995): "Les combustibles de cinq tombes à incinération du deuxième Age du fer à Ensérune (Nissan-lez-Ensérune, Hérault)", Sur les pas des Grecs en Occident, Collection Etudes Massalières 4 (1995): 231-236.

ELVIRA MARTÍN, L.M. y HERNANDO LARA, C. (1989): Inflamabilidad y energía de las especies de sotobosque (Estudio piloto con aplicación a los incendios forestales). INIA, Madrid.

ESQUIVEL, J.A.; CONTRERAS, F.; MOLINA, F. y CAPEL, J. (1991): "Una aplicación de la Teoría de la Información al análisis de datos definidos mediante variables cualitativas multiestado: medidas de similaridad y análisis cluster", Complutum 1(1991): 53-64, Madrid.

GIL, S.; PUYA, M.; VIÑUALES, O.; LUQUE, J.M.; MAIER, J.; FRANCO, C. y HUECAS, J.M (1991): "Informe preliminar sobre el resultado de la excavación de emergencia de la necrópolis tartésica de la Cruz del negro (Carmona, Sevilla)", Anuario Arqueológico de Andalucía 1989, T.III: 611-612. Sevilla.

GRAU ALMERO, E. (1993): "Antracoanálisis de la necrópolis de Cabezo Lucero (Guardamar de Segura, Alicante)", en C. ARANEGUI, A. JODIN, E. LLOBREGAT, P. ROUILLARD y J. UROZ: La nécropole ibérique de Cabezo Lucero (Guardamar de Segura, Alicante), Collection de la Casa de Velázquez 41-Colección Patrimonio 17, Madrid-Alicante, 1993.

MILLER, N.F. (1991): "Interpreting ancient environment and patterns of land use", Actas Primeras Jornadas sobre "Arqueología medioambiental a través de los macrorrestos vegetales", Madrid.

RIVAS MARTÍNEZ, S. (1987): Memoria del mapa de Series de vegetación de España 1:400.000. ICONA, Madrid. 
RODRÍGUEZ-ARIZA, M.O. (1992): Las relaciones hombre-vegetación en el Sureste de la Península Ibérica durante las Edades del Cobre y Bronce a partir del análisis antracológico de siete yacimientos arqueológicos. Tesis doctoral microfilmada. Universidad de Granada.

RODRÍGUEZ-ARIZA, M.O. (1993): "Los procesos de formación y transformación del registro arqueológico en los estudios antracológicos", Arqueología espacial, 16-17, pp. 371-390, Teruel.

RODRÍGUEZ-ARIZA, M.O. (2004): "La antracología: metodología y objetivos", (en prensa).

RODRÍGUEZ-ARIZA, M ${ }^{\mathrm{a}}$ O.; AGUAYO, P. y MORENO, F. (1992): "The environment in the Ronda Basin (Malága, Spain) based on an anthracological study of Old Ronda". Societé Botanique de France, 139, Actualites botaniques (2/3/4), pp.715-725, Paris.

SAINT-LAURENT, J. de (1926): "Étude sur les caractères anatomiques des bois d'Algérie", Bull. St. Rech. Forst. Nord-Afr., I (7): 241-246.

SCHIFFER, M.B. (1976): Behavioral Archaeology. Acacemic Press, New York.

TERRAL, J.F. (1996): "Wild and cultivate olive (Olea europaea L.): a new approach to an old problem using inorganic analyses of modern wood and archaeological charcoal", Review of Paleobotany and Palynology 91: 383-397.

TERRAL, J.F. y ARNOLD-SIMARD, G. (1996): "Beginnings of olive cultivation in Eastern Spain in relation to Holocene bioclimatic changes", Quaternary Research 46: 176-185 


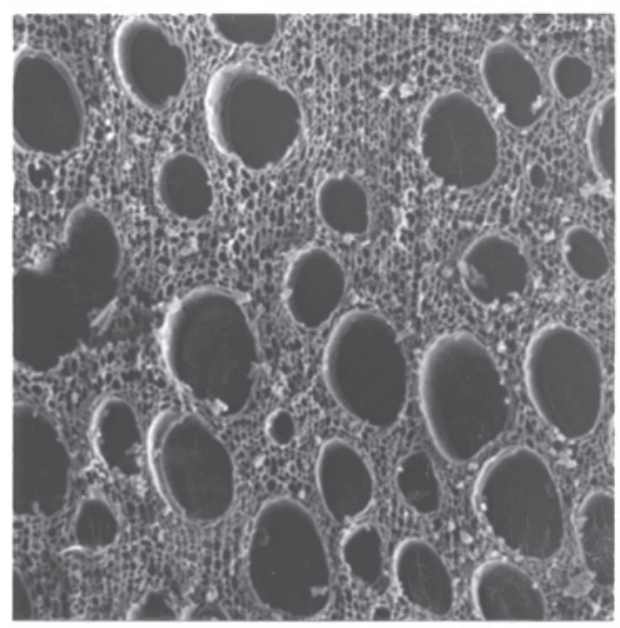

Quercus suber. Plano transversal (X 100)

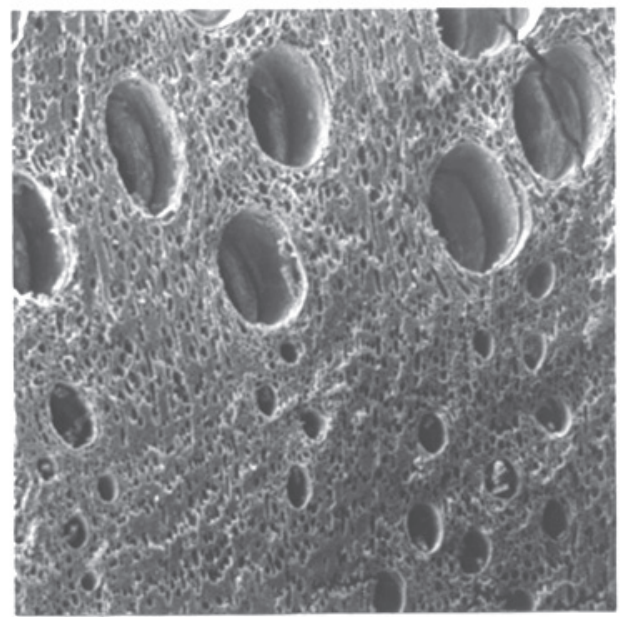

Quercus ilex-coccifera. Plano transversal (X 100)

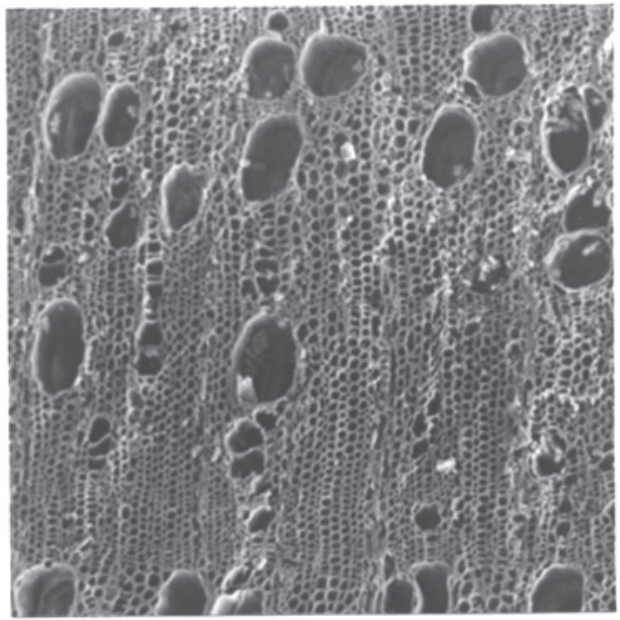

Pistacia terebinthus. Plano transversal (X 100

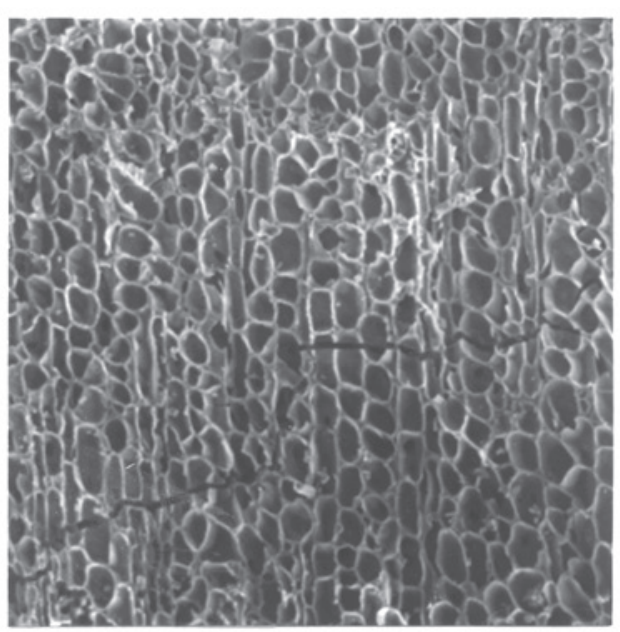

Corcho. (X 100)

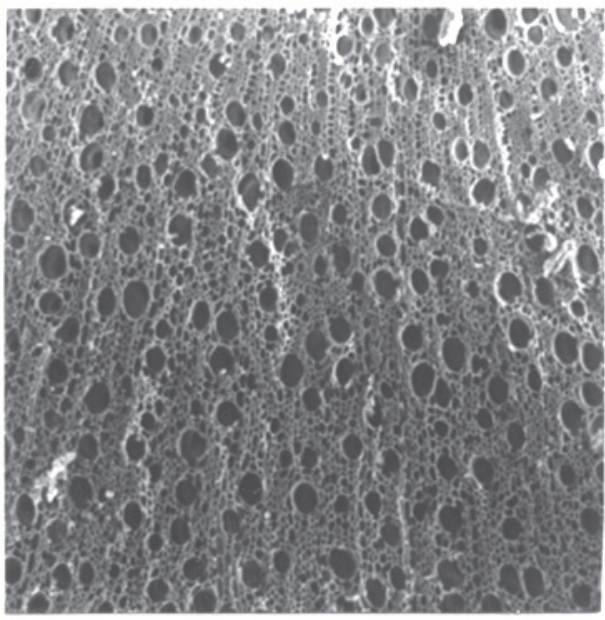

Cistus sp. Plano transversal (X 100)

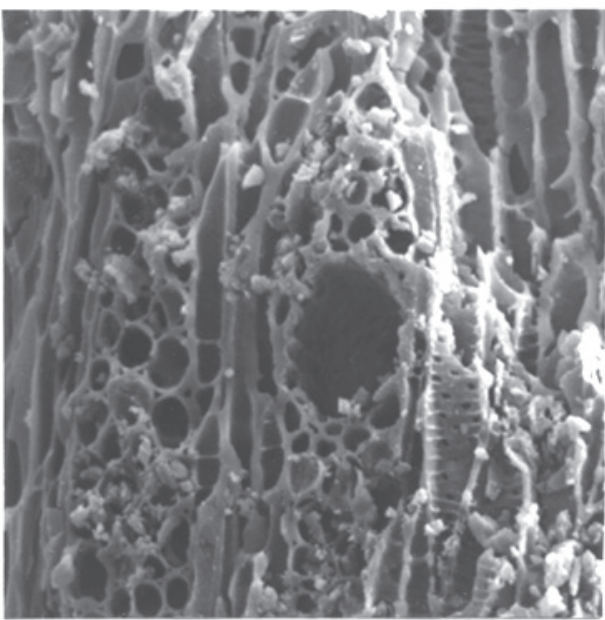

Pistacia terebinthus. P. long. tangencial (X 500)

Lámina I: Microfotografías realizadas con el Microscopio Electrónico de Barrido (SEM) de los taxones determinados en el antracoanálisis de Cruz del Negro.

ISSN: 1133-4525 ISSN-e: 2255-3924 


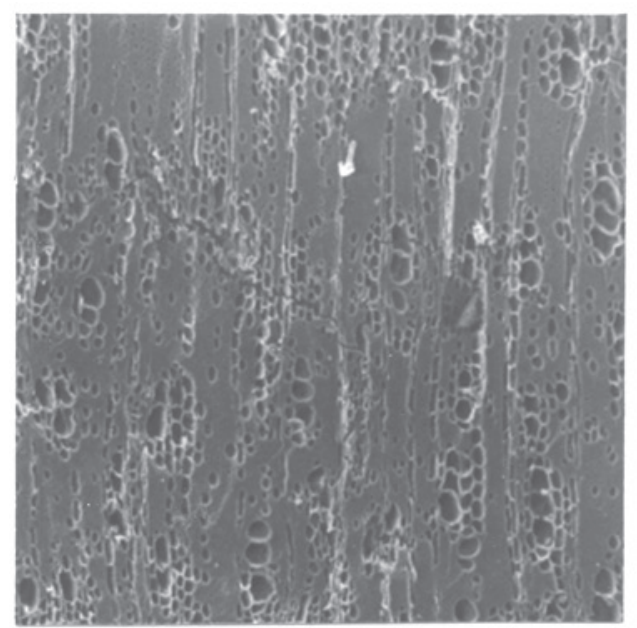

Olea europaea. Plano transversal (X 100)

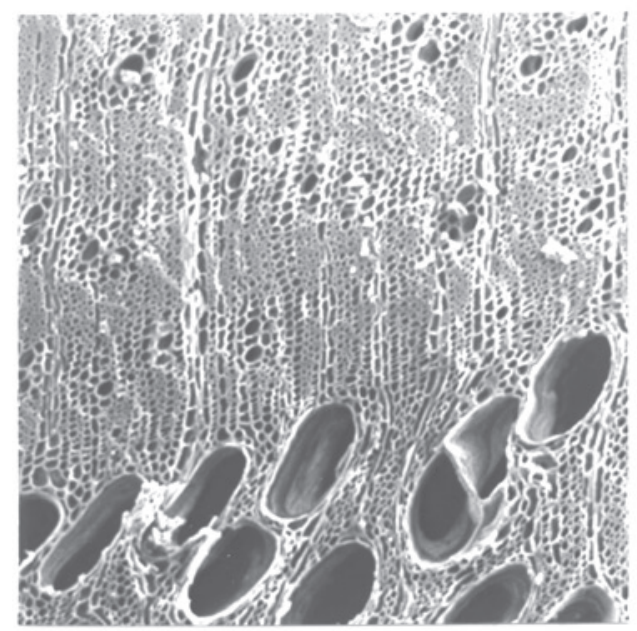

Fraxinus sp. Plano transversal (X I00)

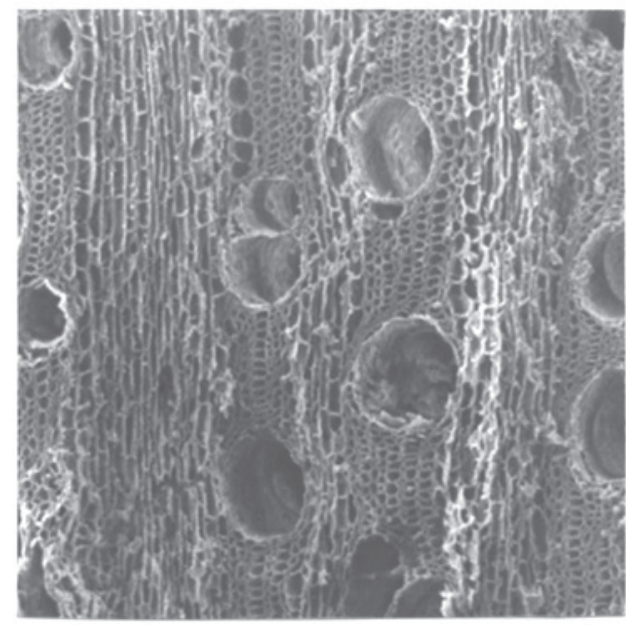

Vitis sp. Plano transversal (X 100)

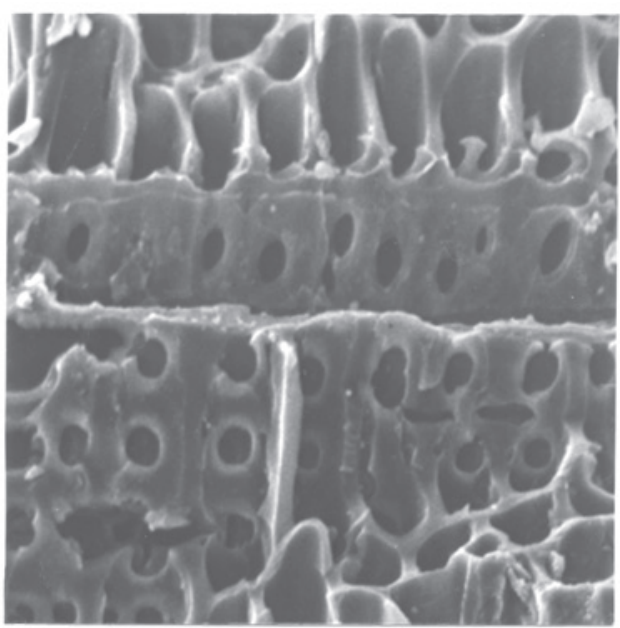

Pinus halepensis. P. long. radial (X 700)

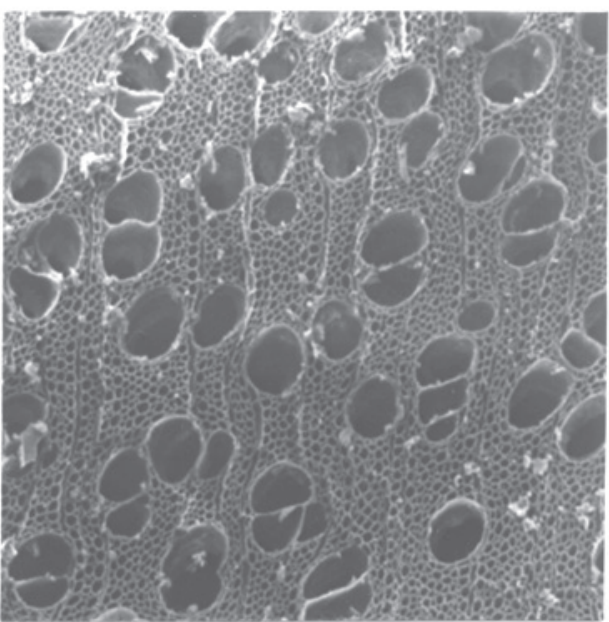

Populus sp. Plano transversal (X 100)

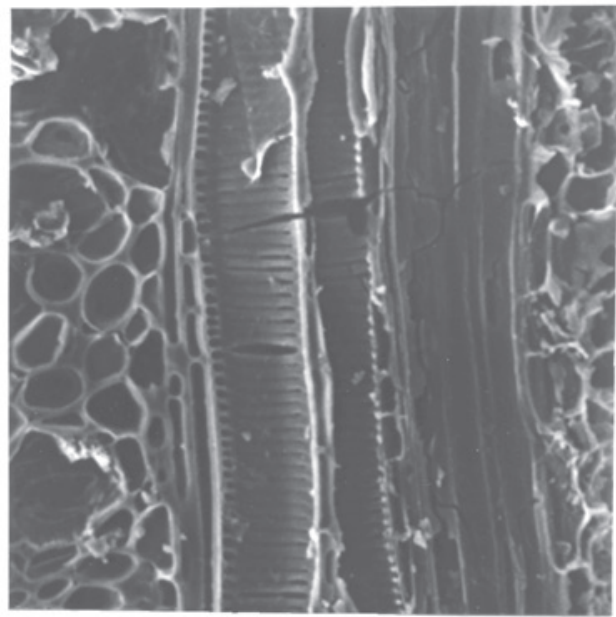

Vitis sp. P. long. tangencial (X 300)

Lámina II: Microfotografías realizadas con el Microscopio Electrónico de Barrido (SEM) de los taxones determinados en el antracoanálisis de Cruz del Negro. 